\title{
A Model for Prioritization of Improvement Opportunities Based on Quality Costs in the Process Interdependency Context
}

\author{
Maja Glogovac ${ }^{1}$, Jovan Filipovic ${ }^{2}$, Nedeljko Zivkovic ${ }^{3}$, Veljko Jeremic ${ }^{4}$
}

\author{
University of Belgrade \\ Jove Ilica 154, Belgrade, Serbia \\ E-mail.1'maja.glogovac@fon.bg.ac.rs, ${ }^{1}$ jovanf@fon.bg.ac.rs, ${ }^{3}$ nedo@fon.bg.ac.rs, ${ }^{4}$ jeremic.veljko@fon.bg.ac.rs
}

cross $^{\text {ref }}$ http://dx.doi.org/10.5755/j01.ee.30.3.14657

\begin{abstract}
Although many modifications and improvements of existing quality cost models were made, there is a lack of approach to quality costing which would take into account the idea of a process-systemic approach regarding the mutual impact of processes through the influence on overall process failure cost. In line with the importance of process management for quality improvements, the PAF, as the most systematic and logical quality cost model, is used in this paper on the level of processes, aiming at developing a model for prioritization of process improvement opportunities. The proposed model is based on comparing different quality costs variants in the process-systemic context that takes the process interdependency into account. The elements of quality costs in the model are considered in relation to the outputs of the processes, where the principle that one process affects the quality of another process by its outputs is taken into account. That is why the failure costs of the affected processes should also be assigned to the quality costs of the observed process. In that way, the model identifies processes that generate the highest quality costs in the system and hence indicate the highest ranked improvement opportunity. Using the factors proposed in the Process cost model, costs are identified and calculated for each process in two moments: the current (before improvements) and desired (after improvements). Improvements are implemented on the basis of the causes of nonconformity analysis and according to the PAF model assumption that preventive and appraisal activities reduce failure costs and the total costs of quality. The difference between the total costs of quality in two observed moments is seen as the greatest possible quality cost reduction for the observed process. This value is used as a criterion for ranking the processes according to their priority for improvements, taking into account the assumption of the PAF model that greater costs mean lower quality and hence a higher priority for improvement.
\end{abstract}

Keywords: Quality Costs; PAF model; Process Approach; Nonconformities Analysis; Cost Reduction.

\section{Introduction}

Continuous improvement is one of the crucial points for companies in nowadays' competitive environments (Voros, 2013; Jurburg et al., 2017). Recent changes in the economic environment such as demanding customers, globalization processes, economic crisis, regulatory issues, etc. are creating pressure on companies and their performances, so business process improvement projects have become a necessity for companies (Bakotic \& Krnic, 2017). Companies need to focus on continuous improvement through selecting and prioritizing process improvement initiatives, that can be a challenging task, especially when multiple decision factors are involved (Aqlan \& Al-Fandi, 2018). Continuous improvement encompasses a spectrum of activities, methods and approaches that seek to improve the effectiveness and efficiency of business processes over time and ensure the alignment of business processes with the competitive environment (Matthews et al., 2017).

Cost of quality (CoQ) is a methodology that allows an organization to determine the extent to which its resources are used for preventing poor quality, appraising the quality level, as well as, managing failures. Having such information allows an organization to determine the potential savings to be gained by implementing process improvements (Rehacek, 2018). In line with this, cost of quality is seen as a reliable indicator associated with the achievement or non-achievement of quality improvements (Sansalvador \& Brotons, 2013; Djekic et al., 2014) and has proven to be useful as an overall measure of organizational performance (Fassoula, 2005; Lari \& Asllani, 2013). It has been demonstrated that measuring quality costs facilitates room for quality improvements and guidelines for implementing a total quality management (TQM) program (Jaju et al., 2009). Today, quality cost management is seen as one of the most important aspects in the development of a quality management system (Martínez \& Selles, 2015). Most examples confirm that quality improvement and cost measurement processes bring about a large reduction in a company's total cost of quality (Vaxevanidis \& Petropoulos, 2008). Thus, quality cost optimization becomes an important effort in attempting to achieve adequate quality improvements. Some authors (e.g. Oppermann et al., 2003; Abdul-Kader et al., 2010; Lim C, 2015; Lim T. K et al., 2015) gave proposals for quality cost optimization in different process environments.

In order to function effectively, an organization must identify and manage a number of inter-related processes, where outputs from one process are often direct inputs into other processes (ISO 9001:2015). In this context, the process approach implies the application of a system of processes within the organization, together with the identification and interaction of these processes, as well as 
managing them in order to achieve the desired results. Since organizational systems encompass the sets of interrelated processes, systemic approach is important since it points out the importance of the operation of system elements without barriers between them, emphasizing that the behavior of any part of the system has an impact on the behavior of the system as a whole. Inputs into the process could also be the causes of nonconformities (BS 6143 Part 1, 1990). Since outputs from one process could be inputs into another process, it could be concluded that one process with a nonconforming output may result in an increase in quality costs of another process. This happens if nonconforming output enters into the process that follows it, and increases the cost of solving nonconformities.

The costs of nonconformities are the key quality costs category because they provide an opportunity for the greatest reduction in total costs (Juran \& Gryna, 1998).

In line with this, the aim of this paper is to develop a specific proactive quality cost model for prioritization of process improvement opportunities. In the model, different quality costs variants could be compared in the processsystemic context based on the process interdependency.

Accordingly, the following research questions were established:

- The first research question was established to determine if the process-systemic approach, according to which one process affects the quality of other processes by its outputs, is usable as a basis for quality costs modeling;

- The second research question was established to determine whether the quality cost model based on the process-systemic approach can be used for determining process quality costs and compared to the reference values, aiming at observing them as mutually comparable values;

- The third research question was established to determine if it is possible to use such model for comparison and ranking of different variants of total quality cost.

Methods used for model conceptualization are as follows: description, used to describe concepts of importance in the field of quality costs, explaining their features and relationships; comparative analysis, used to compare existing scientific approaches in the field of quality costs and define model assumptions; analysis and synthesis, used in the model development, through searching for parts of the whole, the recognition of cause and effect relations among the parts, and through the examination of the functions of certain parts and their behavior within a whole. The model was developed using some elements of PAF model and the idea of the Process model, as well as the relevant literature conclusions, explained within the Basic assumptions of the model.

Experts' evaluation, as the method for evaluating different models, is used by many authors (e.g. Dybå, 2000; Caro et al., 2001; Boyce et al., 2012). Thus, after the model conceptualization, it was evaluated by 50 experts in the field of quality management through the questionnaire consisting of 23 questions about the value and practicality of using the proposed model. Comments and suggestions were thoroughly used for the final model improvement.

In order to make some observations and conclusions about the model behavior in practice, it was applied in a real company. The resulting data were processed in MS Office 2007.
Since the model is based on the process-systemic approach with nonconformity analysis, it can be used to calculate process quality costs more effectively and to compare different process-related cost variants. Results of the model application can be used as a basis for making adequate decisions regarding process management and improvement. Furthermore, results of comparing different quality cost variants can be a useful input in other methods such as e.g. failure mode and effects analysis (FMEA) or quality function deployment (QFD).

\section{Literature Review}

The oldest and most frequently used quality cost model is PAF (introduced by Feigenbaum (1956) and Masser (1957)), which categorizes all the quality costs into: Prevention costs $(\mathrm{P})$, the costs of any action taken to investigate, prevent and reduce the risk of nonconformity or defect; Appraisal costs (A), the costs involved in evaluating the achievement of quality requirements at any stage of the quality loop; Internal failure costs (iF), the costs that arise within an organization due to nonconformities that occur before the product is shipped or delivered; External failure costs $(\mathrm{eF})$, the costs arising due to nonconformities after the product is shipped or delivered (BS 6143 Part 2, 1990).

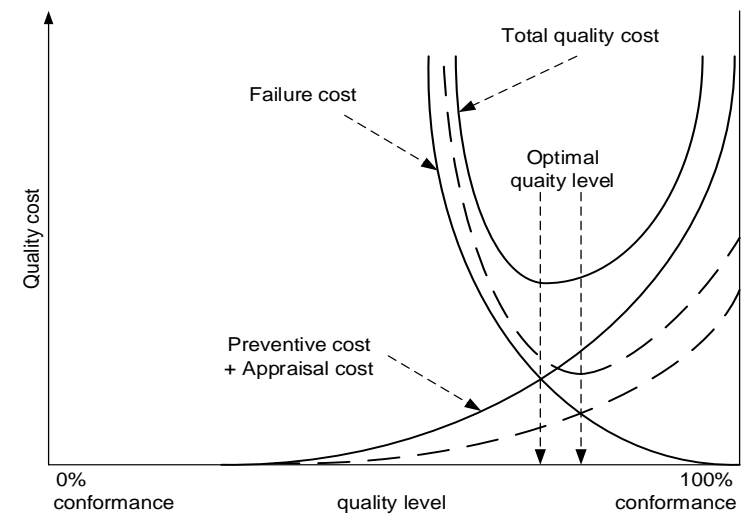

Figure 1. The PAF Model, with the Effect of Introducing New Knowledge and Technologies (Adapted from Fine, 1986)

Soon after, Crosby's model (Crosby, 1979) appeared. In it, the cost categories are, in fact, equal to those in the PAF model. Crosby defines the cost of quality as the sum of the price of conformance (the cost involved in making certain that things are done right the first time, which includes actual prevention and appraisal costs) and price of non-conformance (the money wasted when work fails to conform to customer requirements, which corresponds to the failure costs in the PAF model.

After he recognized the importance of intangible costs, Juran (et al., 1975) revised his PAF model to include the cost of intangibles. Then, Sandoval-Chavez \& Beruvides (1998) created the opportunity/intangible cost model, incorporating opportunity/intangible costs into the traditional PAF model.

In view of a number of drawbacks of the PAF model, Ross (1977) developed the process cost model (Figure 2) as a quality cost system that focuses on the process rather than products or services. 


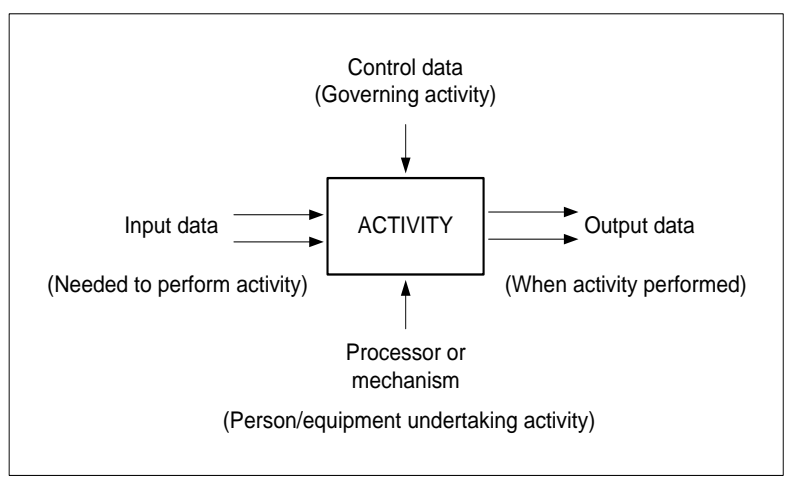

Figure 2. The Structure of the Process Cost Model (BS 6143 Part 1, 1990)

The process cost, in this context, is the total cost of conformance and non-conformance for a particular process, where: the cost of conformance is the actual process cost of producing products or services for the first time to the required standards by a given specified process; the cost of nonconformance is the failure cost associated with the process not being executed to the required standard.

The activity based costing (ABC) method was proposed by Cooper \& Kaplan (1988). The long-term goals of the ABC framework are to eliminate non-value added activities and to continuously improve processes, activities and quality so that no defects are produced (Schiffauerova \& Thomson, 2006) and to help continuous improvement in processes, activities and quality by eliminating non-value added activities (Cokins \& Harris, 2006). One serious limitation of the ABC approach is the need to conduct a full-blown activity-based costing analysis to identify and rank each activity (Vaxevanidis \& Petropouolos, 2008).

Generally, in the literature, it is considered that traditional cost accounting methods do not provide accurate cost data for the measurement of quality costs (Ozkan \& Karaibrahimoglu, 2013). Based on the further literature review, the PAF model can be considered as the most systematic and logical approach to identifying the elements that make up the cost of poor quality, but it considers quality costs as the sum of all cost elements of the organizational system. However, instead of just finding out the overall costs, the CoQ concept should also be used for identifying the quality costs for each process. Although the Process cost model can be used, it does not clearly indicate the costs incurred when the product fails inside the factory walls and after it is delivered to the customer.

Notwithstanding these models have been applied in practice, and many modifications and improvements were made, the relevant literature shows a lack of approach to quality costs which would take into account the idea of a process-systemic approach regarding the mutual impact of processes within an organizational system through the influence on failure cost, as an dominant category of quality cost. Besides, the biggest change in ISO 9001:2015 is that it incorporates risk-based thinking (Goetsch \& Davis, 2016), which enables an organization to determine the factors that could cause its quality management system to deviate from planned results, to put in place preventive controls to minimise negative effects, and to make maximum use of opportunities as they arise (ISO 9001:2015). Shifting from a reactive defect-centric approach to a proactive risk-based quality management system (QMS) reduces failures and lowers the cost of quality (Yim, 2014). The requirements of the latest version of ISO 9001 stress prioritizing risks to drive measurable, cost-saving performance improvements (Brown \& Siegrist, 2016).

Besides, there are indirect processes that are increasingly contributing to the total cost, but they are less assessable than direct processes due to the complex organizational management structure. Therefore, companies aiming at overall improvements need decision support methods to indicate which indirect process needs to be improved and to what extent (Ihrig et al., 2017). Furthermore, an important decision for many managers is how much to invest in cost reducing process improvement (Veldman \& Gaalman, 2015). Some framework for prioritizing process improvement initiatives in manufacturing environments is proposed by Aqlan \& AlFandi (2018) aiming at considering process variables, resource constraints, and operator skills.

However, the situation in the practice still does not show that it is entirely adequate (Glogovac \& Filipovic, 2017). In fact, quality management in all, or almost all, processes are implemented in only about $30 \%$ of the companies, while a significant majority (72 \%) of respondents point out that their companies do not apply any of the quality cost models. The results showed that only 26 $\%$ of respondents achieve a reduction of the quality cost amount, as opposed to the majority that records stagnation, oscillation, or even an increase in these costs. The study pointed out that $64 \%$ of companies would rather observe quality costs at the process level that the level of departments or the whole organizational system. Furthermore, the results also prove that companies with a high QMS maturity level tend to observe quality costs at the process/activity level (77.2\% of them), while $22.8 \%$ of them manage CoQ at the department level. On the other hand, the majority of companies with a low QMS maturity level tend to observe quality costs at the department level (61.1\% of them). Such results indicate a significant necessity for application of process-oriented quality cost models.

\section{Basic Assumptions of the Model}

Since the PAF model is still the most systematic and logical approach to identify and categorize quality costs, the model developed in this paper will partly rely on the PAF model with the goal of identifying the elements that can be considered as quality costs, as well as assigning the category to which the individual cost elements belong, in order to apply the findings on the nature of their behavior. Since, on the other hand, process management is an important TQM principle, the PAF model is used in this paper on the level of processes in order to identify processes that generate the highest quality costs and hence indicate the improvement opportunity. Each process consists of certain activities that can be classified as (Vaxevanidis \& Petropoulos, 2008): basic (core activities that provide only the creation of output without guaranteeing its quality or a higher probability of detecting any nonconforming output early), preventive (aiming to 
increase the probability of creating conformed output) or appraisal (activities being performed in order to detect nonconformities as soon as possible). There are also activities due to an elimination of nonconformities before the product reaches the customers (internal failure costs), or after that (external failure costs). In line with this, as well as the PAF categories, the activities can be considered as elements of quality costs. It is suggested that these costs are calculated according to the elements engaged in their realization, proposed in the Process cost model (BS 6143 Part 1, 1990): employees, equipment, materials and the environment. Similar to the quality costs categories description given by Juran \& Gryna (1998) dividing the costs into direct and indirect and Feigenbaum (1956) pointing out the existence of costs as consequences of nonconformities, the conclusion is that the failure costs (both internal and external) may be observed using two subcategories: direct costs, as the costs of resolving the nonconformities, which therefore depend on their number (mostly re-work for internal failure cost; and dealing with customer complaint for external failure costs), so the factors proposed in BS 6143 Part 1, 1990 can be used to calculate them; and indirect costs, as the consequences of nonconformities but do not affect their resolving so do not necessarily depend on the number of nonconforming outputs (e.g. production downtime, decrease in employee productivity, etc. for internal failure cost; and loss of customers, lowering of the company's reputation, etc. for external failure costs). It is more difficult to measure indirect costs, and they are often not in the standard accounting systems, which is why they may be considered as hidden costs. Indirect quality costs may be expressed as potential but unrealized profit for the company (SandovalChavez \& Beruvides, 1998; Schiffauerova \& Thomson, 2006). Several researchers have proposed methods for the quantification and measurement of these costs (e.g. Hassan, 2009; Adil \& Moutawakil, 2012; Sansalvador \& Brotons, 2013; Snieska, et al., 2013).

In the proposed method, costs are identified and calculated for each required process in two moments: the current (before improvements) and desired (after improvements). The difference between the costs of quality in two observed moments, as the value of the greatest possible cost reduction for the process, is used as a criterion for ranking processes according to their priority for improvements. Improvements are implemented according to the PAF model assumptions (figure 1): that investment in preventive (P) and appraisal (A) activities will reduce failure costs $(\mathrm{iF}, \mathrm{eF})$; that further investment in prevention activities $(\mathrm{P})$ will reduce appraisal costs $(\mathrm{A})$; and that internal failure activities (iF) will reduce external failure costs $(\mathrm{eF})$ and consequently the total cost of quality. One recent example of confirming such behavior of quality cost categories is a study conducted by Al-Dujaili (2013).

Furthermore, there is a key cause for the each nonconformity that could be suppressed by prevention which always costs less, so analysis of nonconformity causes may provide an adequate application of the quality costs models (Campanella, 1999). Therefore, selection of preventive and/or appraisal activities to be implemented or improved within the proposed model, as a measure of improvement, is made on the basis of the causes of nonconformity analysis.

An important principle taken into account in the model is the assumption of the process-systemic approach that one process affects the quality of the other processes by its outputs. This means that failure costs related to a particular process are not only those generated in it, but also those generated in the other processes that use its outputs as their inputs. This happens due to nonconformities from the observed processes that are not revealed within it, but go further into the others making more nonconformities. The later the nonconformities are detected in the processes, that is, the closer they are to the product usage by the customer, the greater the costs of such nonconformities will be (Campanella, 1999), especially if they include external failure cost. In line with this, one process can impact many other processes, sometimes in the same way, but sometimes in different ways, which should be considered as different cases of impacts of the observed process. Each organization should establish its own process relations scheme.

\section{Model Application Procedure}

The quality costs of processes in a company should be observed for a specific period of time (usually one year), for the production of "FP" final products divided into " $D$ " deliveries that are delivered to "W" customers (data that can be derived from a company's documentation). Thus, the value "E", as the average number of final products per single delivery, can be calculated as E=FP/D. The quality cost of each process in the company can be calculated through the following steps.

\section{Collecting data:}

1.1. Data about activities of the observed process: Identify all the activities $\left(\mathrm{a}_{1}, \ldots, \mathrm{a}_{\mathrm{R}}\right)$ within the processes that are realized at this moment (column "Activities", Table 1).

Table 1

Data about the Activities of the Process Being Observed

\begin{tabular}{|c|l|c|c|c|}
\hline t & Process under observation: & \multicolumn{3}{|c|}{ Period of time: } \\
\hline $\mathbf{N}_{\mathbf{0}}$ & Activities & $\mathbf{P}$ & $\mathbf{A}$ & $\mathbf{B}$ \\
\hline 1. & Activity 1 & $\mathrm{~Pa}_{1}{ }^{*}$ & & \\
\hline 2. & Activity 2 & & $\mathrm{Aa}_{2}{ }^{*}$ & \\
\hline$\ldots$ & $\ldots$ & & & $\ldots$ \\
\hline $\mathrm{r}$ & Activity $\mathrm{r}$ & & & $\mathrm{Ba}_{\mathrm{r}}{ }^{*}$ \\
\hline$\ldots$ & $\ldots$ & & & $\ldots$ \\
\hline $\mathrm{R}$ & Activity R & & & $\mathrm{Ba}_{\mathrm{R}}{ }^{*}$ \\
\hline
\end{tabular}

*This is an example of activity categorization according to the cost category $(P, A$, or B). Each company should conduct this categorization so that it fits the real situation.

Their costs should be written in the column "P", "A" or "B" (Table 1) depending on the quality cost categories (Pprevention, A-appraisal or B-basic activities) to which the observed activity belongs. When calculating the quality cost for each P, A and B activity, it is necessary to consider the consumption of elements involved in achieving one output from the process, that is, one cycle of that process. Based on the Process cost model (BS 6143 Part 1, 1990), factors such as employees, material, equipment and environment can be taken into account. 
1.2. Data about the process, through its influence on other processes: Outputs from the process have to be identified, as well as the quantity necessary for other processes and/or customers (and other stakeholders) that use the outputs from this process. According to the identified outputs, based on the process relationships, the processes which are influenced by the process should be identified, where there can be more than one case of impact, denoted with $\mathrm{I}_{1}, \ldots, \mathrm{I}_{\mathrm{Z}}$, as explained in the introduction.

For each case of impact (consisted of processes: z1, z2, $\ldots, \mathrm{zX}_{\mathrm{z}}$, which continue on the observed initial process $\mathrm{z} 0$ ), record data about the overall required number of process outputs (number of cycles of that process): $\mathrm{M}_{1}, \ldots, \mathrm{M}_{\mathrm{Z}}$. Then the maximal number of final products which will be influenced by all those outputs is determined separately for each case of impact and denoted as $\mathrm{FP}_{1}, \ldots, \mathrm{FP}_{\mathrm{Z}}$. The number of final products which will be influenced by one output from this process $\left(\mathrm{L}_{1}, \ldots, \mathrm{L}_{\mathrm{Z}}\right)$ should also be determined here. If $\mathrm{M}_{\mathrm{z}}$ number of outputs of observed process is realized within the observed period of time with the goal to realize the $I_{z}$ case of impact and if realization of the $\mathrm{M}_{\mathrm{z}}$ outputs can affects the quality of $\mathrm{FP}_{\mathrm{z}}$ final products (directly creating such products or indirectly affecting their quality or quantity), then $\mathrm{L}_{\mathrm{z}}=\mathrm{FP}_{\mathrm{z}} / \mathrm{M}_{\mathrm{z}}$. Then it is necessary to record data on the number of nonconforming outputs of the process $\left(\mathrm{N}_{1}, \ldots, \mathrm{N}_{\mathrm{Z}}\right)$ in each case of impact, on the basis of the previous data on the behavior of the process. Output from the process may be at a certain level of nonconformities, which can also be taken into account by weighting $\mathrm{N}_{\mathrm{z}}$ value according to the percentage of nonconforming units within one cycle of process realisation. Only the nonconforming outputs that are the result of the observed initial process are recorded here. The number of products which would be influenced by all nonconforming outputs from the process in the z-th case of impact is marked with " $\mathrm{S}_{\mathrm{z}}$ " and calculated as $\mathrm{S}_{\mathrm{z}}=\mathrm{L}_{\mathrm{z}} \cdot \mathrm{N}_{\mathrm{z}}$, and used when calculating costs of nonconformities. $S_{z}$ number also needs to be expressed through the number of deliveries $\left(D_{z}\right)$, where $D_{z}=S_{Z} / E$ and $E$ is the average number of final products in one delivery.

1.3. Data about nonconformities: For each case of impact $\left(\mathrm{I}_{1}, \ldots, \mathrm{I}_{\mathrm{Z}}\right)$, record data about the distribution of $\mathrm{N}_{\mathrm{z}}$ number of nonconforming outputs by the places they are detected $\left(\mathrm{N}_{\mathrm{z} 0}, \mathrm{~N}_{\mathrm{zl}}, \ldots, \mathrm{N}_{\mathrm{zx}_{\mathrm{z}}}\right)$, as shown in Table 2. Possible places of nonconformity detection are the processes within the observed case of impact, including the product usage which takes place at the end of each case of impact. If there are control points (denoted with $\mathrm{KT}_{\mathrm{zx}_{\mathrm{z}}}, \ldots, \mathrm{KTY}_{\mathrm{zx}_{\mathrm{z}}}$ ) within the observed $\mathrm{x}_{\mathrm{z}}$-th process of $\mathrm{I}_{\mathrm{z}}$ case of impact, they should be included as potential place for detection of nonconforming outputs $\left(\mathrm{N}_{\mathrm{KT} 1 . \mathrm{zx} \mathrm{Z}}, \ldots, \mathrm{N}_{\mathrm{KTY}_{\text {.zx }}}\right)$.

Data about Nonconforming Outputs

\begin{tabular}{|c|c|c|c|c|c|c|c|c|c|c|}
\hline \multicolumn{2}{|l|}{$\begin{array}{l}\text { Nonconforming outputs from the } \\
\text { process }\end{array}$} & \multicolumn{4}{|c|}{ Case of impact: $I_{1}$} & $\ldots \mathbf{I}_{\mathrm{z}} \ldots$ & \multicolumn{4}{|c|}{ Case of impact: $\mathbf{I}_{Z}$} \\
\hline \begin{tabular}{r|} 
Number of nonconforming \\
outputs
\end{tabular} & $\mathrm{N}$ & \multicolumn{4}{|c|}{$\mathrm{N}_{1}$} & & \multicolumn{4}{|c|}{$\mathrm{N}_{\mathrm{Z}}$} \\
\hline & & $1 *$ & $2 *$ & 3* & 4* & & $1 *$ & $2 *$ & $3 *$ & $4 *$ \\
\hline \multirow{3}{*}{\multicolumn{2}{|c|}{$\begin{array}{r}\text { Number of nonconforming outputs } \\
\text { detected in the observed initial process } \\
\left(\mathrm{N}_{\mathrm{z} 0}\right)\end{array}$}} & \multirow{3}{*}{$\mathrm{N}_{10}$} & \multirow{3}{*}{$\frac{\mathrm{N}_{10}}{\mathrm{~N}_{1}}$} & $\mathrm{KT} 1_{10}$ & $\mathrm{~N}_{\mathrm{KT} 1.10}$ & & $\mathrm{Nz0}$ & $\frac{\mathrm{N}_{\mathrm{Z} 0}}{\mathrm{~N}_{\mathrm{Z}}}$ & $\mathrm{KT} 1 \mathrm{z} 0$ & NKT1.Z0 \\
\hline & & & & $\ldots$ & & & & & & $\ldots$ \\
\hline & & & & $\mathrm{KTY}_{10}$ & NKTY.10 & & & & KTYZ0 & NKTY. Z0 \\
\hline \multirow{3}{*}{\multicolumn{2}{|c|}{$\begin{array}{r}\text { Number of nonconforming outputs } \\
\text { detected in the first process within } I_{z} \\
\text { case of impact }\left(\mathrm{N}_{\mathrm{z} 1}\right)\end{array}$}} & \multirow{3}{*}{$\mathrm{N}_{11}$} & \multirow{3}{*}{$\frac{\mathrm{N}_{11}}{\mathrm{~N}_{1}}$} & $\mathrm{KT} 1_{11}$ & NKT1.11 & & $\mathrm{NZ1}$ & $\frac{\mathrm{N}_{\mathrm{Z1}}}{\mathrm{N}_{\mathrm{Z}}}$ & $\mathrm{KT} 1 \mathrm{z} 1$ & NKT1. Z1 \\
\hline & & & & & & & & & & \\
\hline & & & & $\mathrm{KTY}_{11}$ & NKTY.11 & & & & KTYZ1 & NKTY. Z1 \\
\hline \multirow{3}{*}{\multicolumn{2}{|c|}{$\begin{array}{r}\text { Number of nonconforming outputs } \\
\text { detected in the second process within } I_{z} \\
\text { case of impact }\left(\mathrm{N}_{\mathrm{z} 2}\right)\end{array}$}} & \multirow{3}{*}{$\mathrm{N}_{12}$} & \multirow{3}{*}{$\frac{N_{12}}{N_{1}}$} & $\mathrm{KT} 1_{12}$ & $\mathrm{~N}_{\mathrm{KT} 1.12}$ & & $\mathrm{Nz} 2$ & $\frac{\mathrm{N}_{\mathrm{Z} 2}}{\mathrm{~N}_{\mathrm{Z}}}$ & $\mathrm{KT} 1 \mathrm{z} 2$ & NKT1. Z2 \\
\hline & & & & $\ldots$ & $\ldots$ & & & & $\ldots$ & $\ldots$ \\
\hline & & & & $\mathrm{KTY}_{12}$ & NKTY.12 & & & & KTYZ2 & NKTY. Z2 \\
\hline \multirow{4}{*}{\multicolumn{2}{|c|}{$\begin{array}{r}\text { Number of nonconforming outputs } \\
\text { detected in the last process within } \mathrm{I}_{\mathrm{z}} \\
\text { case of impact }\left(\mathrm{N}_{\mathrm{zXz}}\right)\end{array}$}} & & & & & & $\ldots$ & & & \\
\hline & & \multirow{3}{*}{$\mathrm{N}_{1 X_{1}}$} & \multirow{3}{*}{$\frac{\mathrm{N}_{1 X_{1}}}{\mathrm{~N}_{1}}$} & $\mathrm{KT}_{1 \mathrm{X}_{1}}$ & $\mathrm{~N}_{\mathrm{KT} 1.1 \mathrm{X}_{1}}$ & & $\mathrm{~N}_{\mathrm{ZX}}$ & $\frac{\mathrm{N}_{\mathrm{Zx}}}{\mathrm{N}_{\mathrm{Z}}}$ & $\mathrm{KT}_{\mathrm{ZX}_{\mathrm{z}}}$ & $\mathrm{N}_{\mathrm{KT} 1 . \mathrm{ZX}}$ \\
\hline & & & & & & & & & & $\ldots$ \\
\hline & & & & $\mathrm{KTY}_{1 \mathrm{X}_{1}}$ & $\mathrm{~N}_{\mathrm{KTY} .1 \mathrm{X}_{1}}$ & & & & $\mathrm{KTY}_{\mathrm{ZX}_{\mathrm{z}}}$ & $\mathrm{N}_{\mathrm{KTY} . Z \mathrm{X}_{\mathrm{Z}}}$ \\
\hline $\begin{array}{l}\text { Number of nonconforming out } \\
\text { detected during product usage ( }\end{array}$ & $\begin{array}{ll}\text { puts } \\
\left.J_{\mathrm{zU}}\right)\end{array}$ & $\mathrm{N}_{1 \mathrm{U}}$ & $\frac{\mathrm{N}_{1 \mathrm{U}}}{\mathrm{N}_{1}}$ & - & - & & $\mathrm{N} Z U$ & $\frac{\mathrm{N}_{\mathrm{ZU}}}{\mathrm{N}_{\mathrm{Z}}}$ & - & - \\
\hline
\end{tabular}

* 1 -Number of nonconformance outputs according to the place of detection, for observed case of impact; 2 - Percentage of nonconformance outputs according to the place of detection, for observed case of impact; 3 -Control point designation; 4 - Number of nonconformance outputs detected in observed control point

1.4. Data about the elements of failure costs: For each case of impact $\left(\mathrm{I}_{1}, \ldots, \mathrm{I}_{\mathrm{Z}}\right)$, that is for each process $\left(\mathrm{z} 0, \ldots, \mathrm{zX}_{\mathrm{z}}\right)$ within the observed case of impact $\left(\mathrm{I}_{\mathrm{z}}\right)$, both internal and external failure costs should be identified (Table 3$)$. Therefore, for each case of impact $\left(\mathrm{I}_{1}, \ldots, \mathrm{I}_{\mathrm{Z}}\right)$, the key stakeholders $\left(\mathrm{SH}_{\mathrm{z} 1}, \ldots, \mathrm{SH}_{\mathrm{zG}}\right)$ of the organizational system should also be identified, for the purpose of a more complete consideration of costs of nonconformities.

When it comes to internal failure costs (iF): these costs for $\mathrm{x}_{\mathrm{z}}$-th process of $\mathrm{I}_{\mathrm{z}}$ case of impact should be calculated using the equation for $\mathrm{iF}_{\mathrm{zx}_{\mathrm{z}} \cdot \mathrm{N}_{\mathrm{z}}}$, as explained within step 2 . For initial process of $I_{z}$ case of impact, those costs are 
Maja Glogovac, Jovan Filipovic, Nedeljko Zivkovic, Veljko Jeremic. A Model for Prioritization of Improvement ...

calculated in accordance with the number of nonconforming outputs from that process $\left(\mathrm{N}_{\mathrm{z}}\right)$. For other processes within the observed case of impact, those costs are calculated in accordance with the number of nonconforming outputs from those processes that appear as a consequence of the $\mathrm{N}_{\mathrm{z}}$ nonconforming outputs from the initial process. Direct internal failure costs are noted within the Table 3 as $\mathrm{iF}\left(\mathrm{RW}_{\mathrm{zx}_{\mathrm{z}}}\right)_{\mathrm{N}_{\mathrm{z}}}$ and imply repeated activities as a minimum of measures to resolve nonconformities within the system. On the other hand, the indirect internal failure costs, as explained in the introduction for the method, may be expressed as an unrealized value that would be realized

Data about Failure Costs Elements

\begin{tabular}{|c|c|c|c|c|c|c|}
\hline 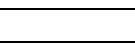 & ailure costs & \multicolumn{2}{|c|}{ Case of impact: $I_{1}$} & $\ldots \mathbf{I}_{\mathrm{z}} \ldots$ & \multicolumn{2}{|c|}{ Case of impact: $I_{z}$} \\
\hline Influe & e on stakeholders & \multicolumn{2}{|c|}{$\mathrm{SH}_{11}, \ldots, \mathrm{SH}_{1 \mathrm{G}}$} & $\mathrm{SH}_{\mathrm{z} 1}, \ldots, \mathrm{SH}_{\mathrm{zG}}$ & \multicolumn{2}{|c|}{$\mathrm{SH}_{\mathrm{Zl}}, \ldots, \mathrm{SH}_{\mathrm{ZG}}$} \\
\hline \multirow{14}{*}{$\begin{array}{l}\text { Internal } \\
\text { Failure } \\
\text { Costs (iF) }\end{array}$} & Direct (for z0) & \multicolumn{2}{|c|}{$\mathrm{iF}\left(\mathrm{RW}_{10}\right)_{\mathrm{N}_{1}}$} & & \multicolumn{2}{|c|}{$\mathrm{iF}\left(\mathrm{RW}_{\mathrm{Z} 0}\right)_{\mathrm{N}_{\mathrm{Z}}}$} \\
\hline & Direct (for z1) & \multicolumn{2}{|c|}{$\mathrm{iF}\left(\mathrm{RW}_{11}\right)_{\mathrm{N}_{1}}$} & & \multicolumn{2}{|c|}{$\mathrm{iF}\left(\mathrm{RW}_{\mathrm{Z1}}\right)_{\mathrm{N}_{\mathrm{Z}}}$} \\
\hline & $\ldots$ & & & & \multicolumn{2}{|c|}{$\ldots$} \\
\hline & Direct (for $z X_{z}$ ) & \multicolumn{2}{|c|}{$\overline{\mathrm{iF}}\left(\mathrm{RW}_{1 \mathrm{X}_{1}}\right)_{\mathrm{N}_{1}}$} & & \multicolumn{2}{|c|}{$\overline{\mathrm{iF}\left(\mathrm{RW}_{\mathrm{ZX}}\right)_{\mathrm{Z}} \cdot \mathrm{N}_{\mathrm{Z}}}$} \\
\hline & Indirect (for z0) & $\mathrm{iF}_{10.1}$ & $\mathrm{iF}_{10.1 . \mathrm{N}_{1}}$ & & $\mathrm{iF}_{\mathrm{Z} 0.1}$ & $\mathrm{iF}_{\mathrm{Z} 0.1 . \mathrm{N}_{\mathrm{Z}}}$ \\
\hline & & $\ldots$ & $\ldots$ & & $\ldots$ & $\ldots$ \\
\hline & & $\mathrm{iF}_{10 . \mathrm{H}}$ & $\mathrm{iF}_{10 . \mathrm{H} . \mathrm{N}_{1}}$ & & $\mathrm{iF}_{\mathrm{Z} 0 . \mathrm{H}}$ & $\overline{\mathrm{iF}_{\mathrm{Z} 0 . \mathrm{H} . \mathrm{N}_{\mathrm{Z}}}}$ \\
\hline & Indirect (for z1) & $\mathrm{iF}_{11.1}$ & $\mathrm{iF}_{11.1 . \mathrm{N}_{1}}$ & & $\mathrm{iF}_{\mathrm{Z} 1.1}$ & $\mathrm{iF}_{\mathrm{Z1.1.N}}$ \\
\hline & & $\ldots$ & $\ldots$ & & $\ldots$ & $\ldots$ \\
\hline & & $\mathrm{iF}_{11 . \mathrm{H}}$ & $\mathrm{iF}_{11 . \mathrm{H} . \mathrm{N}_{1}}$ & & $\mathrm{iF}_{\mathrm{Z1} \cdot \mathrm{H}}$ & $\mathrm{iF}_{\text {Z1.H.N }}$ \\
\hline & $\ldots$ & & & & & \\
\hline & Indirect (for $\mathrm{zX}$ ) & $\mathrm{iF}_{1 X_{1} \cdot 1}$ & $\mathrm{iF}_{1 X_{1} \cdot 1 . \mathrm{N}_{1}}$ & & $\mathrm{iF}_{\mathrm{ZX}}$ & $\mathrm{iF}_{\mathrm{ZX}} \cdot 1 \cdot \mathrm{N}_{\mathrm{Z}}$ \\
\hline & & $\ldots$ & $\ldots$ & & $\ldots$ & $\ldots$ \\
\hline & & $\mathrm{iF}_{1 X_{1} \cdot \mathrm{H}}$ & $\mathrm{iF}_{1 \mathrm{X}_{1} \cdot \mathrm{H} \cdot \mathrm{N}_{1}}$ & & $\mathrm{iF}_{\mathrm{ZX}} \cdot \mathrm{H}$ & $\mathrm{iF}_{\mathrm{ZX}} \cdot \mathrm{H} \cdot \mathrm{N}_{\mathrm{Z}}$ \\
\hline \multirow{4}{*}{$\begin{array}{l}\text { Internal } \\
\text { Failure } \\
\text { Costs (eF) }\end{array}$} & Direct (for zU) & \multicolumn{2}{|c|}{$\mathrm{eF}\left(\mathrm{SH}_{11}\right)_{\mathrm{N}_{1}}+\ldots+\mathrm{eF}\left(\mathrm{SH}_{1 \mathrm{G}}\right)_{\mathrm{N}_{1}}$} & $\ldots$ & \multicolumn{2}{|c|}{$\mathrm{eF}\left(\mathrm{SH}_{\mathrm{Zl}}\right)_{\mathrm{N}_{\mathrm{Z}}}+\ldots+\mathrm{eF}\left(\mathrm{SH}_{\mathrm{ZG}}\right)_{\mathrm{N}_{\mathrm{Z}}}$} \\
\hline & \multirow{3}{*}{ Indirect (for zU) } & $\mathrm{eF}_{1 \mathrm{U} .1}$ & $\mathrm{eF}_{1 \mathrm{U} .1 . \mathrm{N}_{1}}$ & & $\mathrm{eF}_{\mathrm{ZU} .1}$ & $\mathrm{eF}_{\mathrm{ZU} \cdot 1 . \mathrm{N}_{\mathrm{Z}}}$ \\
\hline & & $\ldots$ & $\ldots$ & & $\ldots$ & $\ldots$ \\
\hline & & $\mathrm{eF}_{1 \mathrm{U} . \mathrm{D}}$ & $\mathrm{eF}_{1 \mathrm{U} . \mathrm{D} . \mathrm{N}_{1}}$ & & $\mathrm{eF}_{\mathrm{ZU} . \mathrm{D}}$ & $\mathrm{eF}_{\text {ZU.D.N }}$ \\
\hline
\end{tabular}

if the planned product quantity had been produced, that is if a cause of the cost (e.g. delay in production) had not happened. Types of indirect iF costs for one cycle of realization of $\mathrm{x}_{\mathrm{z}}$-th process within $\mathrm{I}_{\mathrm{z}}$ case of impact are written on the left side $\left(\mathrm{iF}_{\mathrm{zx}_{\mathrm{z}} \cdot 1}, \ldots, \mathrm{iF}_{\mathrm{zx}_{\mathrm{z}} \cdot \mathrm{H}}\right)$. The amounts of these costs, that appear as a consequence of the $\mathrm{N}_{z}$ nonconforming outputs, are recorded on the right side $\left(\mathrm{iF}_{\mathrm{zx}_{\mathrm{z}} \cdot 1 . \mathrm{N}_{\mathrm{Z}}}, \ldots, \mathrm{iF}_{\mathrm{zx}_{\mathrm{z}} \cdot \mathrm{H} \cdot \mathrm{N}_{\mathrm{Z}}}\right)$, within the same column.

When it comes to external failure costs $(\mathrm{eF})$ : they are calculated with the equation $\mathrm{eF}_{\mathrm{zU} \cdot \mathrm{N}_{\mathrm{z}}}$, as explained within the step 2. Direct external failure costs, denoted with $\mathrm{eF}\left(\mathrm{SH}_{\mathrm{zg}}\right)_{\mathrm{N}_{\mathrm{Z}}}$, imply activities related to the resolving nonconformities detected outside the system and should be determined for the number of nonconforming final products caused by nonconforming outputs from the initial process within each case of impact. Those costs are divided into the average number of deliveries $\left(D_{z}\right)$, where one delivery means one or more processes of dealing with complaints from $\mathrm{SH}_{\mathrm{zg}}$ stakeholder. Indirect external failure costs can be expressed as unrealized value (e.g. income) associated with the number of final products which could be produced and sold if a cause of the cost (e.g. loss of customer) had not happened. They are related to the number of customers affected by nonconforming products, whereby the costs of losing one customer can be expressed through the $\mathrm{Q} / \mathrm{W}$ relation. Types of indirect eF costs for $I_{z}$ case of impact, related to one delivery of final products, are written on the left side $\left(\mathrm{eF}_{\mathrm{zU} .1}, \ldots, \mathrm{eF}_{\mathrm{zU} . \mathrm{D}}\right)$ and amounts of those costs are written on the right side $\left(\mathrm{eF}_{\mathrm{zU} \cdot 1 . \mathrm{N}_{\mathrm{z}}}, \ldots, \mathrm{eF}_{\mathrm{zU} \cdot \mathrm{D} \cdot \mathrm{N}_{\mathrm{Z}}}\right)$, within the same column.

2. Determining costs of quality: On the basis of the PAF model, total quality costs (CoQ) in the observed moment can be expressed as:

$$
\mathrm{CoQ}=\mathrm{P}_{\mathrm{M}}+\mathrm{A}_{\mathrm{M}}+\mathrm{F}_{\mathrm{N}}
$$

$\mathbf{P}_{\mathbf{M}}$ - overall prevention costs in the observed period of time for $\mathrm{M}$ process outputs

$\mathbf{A}_{\mathbf{M}}$ - overall appraisal costs in the observed period of time for $\mathrm{M}$ process outputs

$\mathbf{F}_{\mathbf{N}}$ - overall internal and external failure costs in the observed period of time for $\mathrm{N}$ nonconforming process outputs (explained in detail by equation 6)

$\mathbf{N}$ - overall number of nonconforming outputs from the initial process in the observed period of time (explained in detail by equation 7)

M - overall required number of outputs from the observed process, that is the number of cycles of process realization in order to make the required number of final products, within the observed period of time. It consists of:

$$
\mathrm{M}=\sum_{\mathrm{z}=1}^{\mathrm{Z}} \mathrm{M}_{\mathrm{z}}
$$


$\mathbf{Z}$ - number of cases of impact of the observed process on other processes within the organizational system $(\mathrm{z}=1, \ldots, \mathrm{Z})$

$\mathbf{M}_{\mathbf{z}}$ - overall required number of observed process outputs, that is, the required number of cycles of its realization, which is related to the observed $\mathrm{z}$-th case of impact

Further, amounts of prevention cost $\mathrm{P}_{\mathrm{M}}$, appraisal cost $A_{M}$, as well as basic cost $B_{M}$ (as a part of failure cost $F_{M}$ ) can be expressed as:

$$
\begin{aligned}
& P_{M}=\sum_{i=1}^{I} P_{a_{i} \cdot M}=\sum_{i=1}^{I} P_{a_{i}} \cdot M \\
& A_{M}=\sum_{j=1}^{J} A_{a_{j} \cdot M}=\sum_{j=1}^{J} A_{a_{j}} \cdot M \\
& B_{M}=\sum_{k=1}^{K} B_{a_{k} \cdot M}=\sum_{k=1}^{K} B_{a_{k}} \cdot M
\end{aligned}
$$

$\mathbf{i}=1, \ldots, \mathrm{I}-$ includes only those activities $\mathrm{a}_{1}, \ldots, \mathrm{a}_{\mathrm{R}}$ of the observed process that belong to prevention costs

$\mathbf{j}=1, \ldots, \mathrm{J}-$ includes only those activities $\mathrm{a}_{1}, \ldots, \mathrm{a}_{\mathrm{R}}$ of the observed process that belong to appraisal costs

$\mathbf{k}=1, \ldots, \mathrm{K}-$ includes only those activities $\mathrm{a}_{1}, \ldots, \mathrm{a}_{\mathrm{R}}$ of the observed process that belong to basic costs

$\mathbf{P}_{\mathbf{a}_{\mathrm{i}}, \mathbf{M}}-$ cost of $\mathrm{i}$-th preventive activity, for $\mathrm{M}$ outputs

$\mathbf{A}_{\mathbf{a}_{\mathrm{j}}, \mathbf{M}}-$ cost of $\mathrm{j}$-th appraisal activity, for $\mathrm{M}$ outputs

$\mathbf{B}_{\mathbf{a}_{\mathbf{k}} \cdot \mathbf{M}}-$ cost of k-th basic activity, for $\mathbf{M}$ outputs

For calculating failure costs, the impact on quality of other processes has to be taken into account through one or more existing cases of impact:

$$
\mathrm{F}_{\mathrm{N}}=\sum_{\mathrm{z}=1}^{\mathrm{Z}} \mathrm{F}_{\mathrm{z} \cdot \mathrm{N}_{\mathrm{z}}}
$$

$\mathbf{F}_{\mathbf{z .}} \mathbf{N}_{\mathbf{z}}$ - overall failure costs (internal and external) in

the $\mathrm{z}$-th case of impact, that appear as a consequence of $\mathrm{N}_{\mathrm{z}}$ nonconforming outputs, recorded in that case of impact

$\mathbf{N}$ - overall number of nonconforming outputs from the observed initial process within the given period of time, as a sum of nonconforming outputs from all the cases of impact related to the observed process:

$$
\mathrm{N}=\sum_{\mathrm{z}=1}^{\mathrm{Z}} \mathrm{N}_{\mathrm{z}}
$$

$\mathbf{N}_{\mathbf{z}}$ - number of nonconforming outputs from the observed initial process in the z-th case of impact, as a sum of nonconforming outputs detected in each process of that case of impact, which are denoted with $\mathrm{N}_{\mathrm{zx}_{2}}$

$\mathbf{N}_{\mathbf{z x}}$, as a number of nonconforming outputs from the observed process that are detected in $\mathrm{x}_{\mathrm{Z}}$-th process within the z-th case of impact, can be:

- $\mathbf{N}_{\mathbf{z 0}}$ - number of nonconforming outputs revealed in the observed initial process

- $\quad \mathbf{N}_{\mathbf{z 1}}$ - number of nonconforming outputs revealed in the first process, after the initial process, of the z-th case of impact
- $\mathbf{N}_{\mathbf{z} 2}$ - number of nonconforming outputs revealed in the second process of the z-th case of impact

- ...

- $\quad \mathbf{N}_{\mathbf{z X}} \mathbf{X}_{\mathbf{z}}$ - number of nonconforming outputs revealed in the last process of the z-th case of impact

- $\quad \mathbf{N}_{\mathbf{z U}}$ - number of nonconforming outputs from the observed process in the z-th case of impact that are revealed during the product usage

$\mathbf{X}_{\mathbf{z}}$ - number of processes that make the observed case of impact $\left(\mathbf{x}_{\mathbf{z}}=0, \ldots, \mathrm{X}_{\mathrm{z}}\right)$

$\mathbf{F}_{\mathbf{z . N _ { \mathbf { z } }}}$, as a total failure cost in the $\mathrm{z}$-th case of impact, consists of the sum of all the internal failure and external failure cost for that case of impact.

When it comes to the internal failure cost:

$\mathbf{i F}_{\mathbf{z x}_{\mathbf{z}} \cdot \mathbf{N}_{\mathbf{z}}}$ are internal failure costs of the $\mathrm{x}_{\mathrm{z}}$-th process within the $z$-th case of impact that appears as a consequence of $\mathrm{N}_{\mathrm{z}}$ nonconforming outputs, when the nonconformities are detected within the system (after the $\mathrm{X}_{\mathrm{Z}}$-th process). They consist of two subcategories:

$$
\mathrm{iF}_{\mathrm{zx}_{\mathrm{z}} \cdot \mathrm{N}_{\mathrm{z}}}=\text { direct } \mathrm{iF} \text { cost }+ \text { indirect } \mathrm{iF} \text { cost }
$$

As explained in more detail in the introduction, the direct iF costs include repeated activities due to resolving nonconformities revealed within the system and they consist of the sum of the relevant costs of the P, A and B activities. The indirect $\mathrm{iF}$ costs are related to the consequences of the occurrence of nonconformities. Therefore, for $\mathrm{x}_{\mathrm{z}}$-th process of the $\mathrm{z}$-th case of impact, internal failure costs are calculated as:

$$
\begin{aligned}
& \mathrm{iF}_{\mathrm{zx}_{\mathrm{z}} \cdot \mathrm{N}_{\mathrm{z}}}=\sum_{\mathrm{i}=1}^{\mathrm{I}} \mathrm{P}_{\mathrm{a}_{\mathrm{i}} \cdot \mathrm{zx} \mathrm{x}_{\mathrm{z}} \cdot \mathrm{N}_{\mathrm{z}}}+\sum_{\mathrm{j}=1}^{\mathrm{J}} \mathrm{A}_{\mathrm{a}_{\mathrm{j}} \cdot \mathrm{zx} \mathrm{z} \cdot \mathrm{N}_{\mathrm{z}}}+\sum_{\mathrm{k}=1}^{\mathrm{K}} \mathrm{B}_{\mathrm{a}_{\mathrm{k}} \cdot \mathrm{zx}_{\mathrm{z}} \cdot \mathrm{N}_{\mathrm{z}}}+\sum_{\mathrm{h}=1}^{\mathrm{H}} \mathrm{iF}_{\mathrm{zx}_{\mathrm{z}} \cdot \mathrm{h} \cdot \mathrm{N}_{\mathrm{z}}} \\
& \sum_{\mathrm{i}=1}^{\mathrm{I}} \mathrm{P}_{\mathrm{a}_{\mathrm{i}} \cdot 2 \mathrm{x}_{\mathrm{z}} \cdot \mathrm{N}_{\mathrm{z}}}=\sum_{\mathrm{i}=1}^{\mathrm{I}} \mathrm{P}_{\mathrm{a}_{\mathrm{i}} \cdot 2 \mathrm{zx}_{\mathrm{z}}} \cdot \mathrm{N}_{\mathrm{z} \cdot \mathrm{x}_{\mathrm{z}}} \\
& \sum_{j=1}^{J} A_{a_{j} \cdot z x_{z} \cdot N_{z}}=\sum_{j=1}^{J} A_{a_{j} \cdot z x_{z}} \cdot N_{z \cdot x_{z}} \\
& \sum_{\mathrm{k}=1}^{\mathrm{K}} \mathrm{B}_{\mathrm{a}_{\mathrm{k}} \cdot \mathrm{zx}_{\mathrm{z}} \cdot \mathrm{N}_{\mathrm{z}}}=\sum_{\mathrm{k}=1}^{\mathrm{K}} \mathrm{B}_{\mathrm{a}_{\mathrm{k}} \cdot \mathrm{zx} \mathrm{z}} \cdot \mathrm{N}_{\mathrm{z} \cdot \mathrm{x}_{\mathrm{z}}} \\
& \sum_{\mathrm{h}=1}^{\mathrm{H}} \mathrm{iF}_{\mathrm{zx}_{\mathrm{z}} \cdot \mathrm{h} \cdot \mathrm{N}_{\mathrm{z}}}=\sum_{\mathrm{h}=1}^{\mathrm{H}} \mathrm{iF}_{\mathrm{zx}_{\mathrm{z}} \cdot \mathrm{h}} \cdot \mathrm{N}_{\mathrm{z} \cdot \mathrm{x}_{\mathrm{z}}}
\end{aligned}
$$

$\mathbf{P}_{\mathbf{a}_{\mathbf{i}} \cdot \mathbf{z} \mathbf{z}_{\mathbf{z}} \cdot \mathbf{N}_{\mathbf{z}}}$ - cost of i-th preventive activity of the $\mathrm{x}_{\mathbf{z}}$-th process within the $z$-th case of impact, as a consequence of $\mathrm{N}_{\mathrm{Z}}$ nonconforming outputs of the observed process

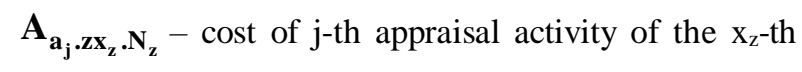
process within the $\mathrm{z}$-th case of impact, as a consequence of $\mathrm{N}_{\mathrm{Z}}$ nonconforming outputs of the observed process

$\mathbf{B}_{\mathbf{a}_{\mathbf{k}} \cdot \mathbf{z x}_{\mathbf{z}} \cdot \mathbf{N}_{\mathbf{z}}}$ - cost of $\mathrm{k}$-th basic activity of the $\mathrm{x}_{\mathrm{z}}$-th process within the $z$-th case of impact, as a consequence of $\mathrm{N}_{\mathrm{z}}$ nonconforming outputs of the observed process

$\mathbf{i F}_{\mathbf{z x}_{\mathbf{z}} \cdot \mathbf{h}}-\mathrm{h}$-th indirect internal failure cost related to the $\mathrm{X}_{\mathrm{z}}$-th process within the $\mathrm{z}$-th case of impact, for one cycle of realization of that process 
Maja Glogovac, Jovan Filipovic, Nedeljko Zivkovic, Veljko Jeremic. A Model for Prioritization of Improvement ...

$\mathbf{i F}_{\mathbf{z x}_{\mathbf{z}} \cdot \mathbf{h} \cdot \mathbf{N}_{\mathbf{z}}}-$ h-th indirect internal failure cost related to the $\mathrm{x}_{\mathrm{z}}$-th process within the $\mathrm{z}$-th case of impact, as a consequence of $\mathrm{N}_{\mathrm{z}}$ nonconforming outputs of the observed initial process

$\mathbf{H}$ - number of indirect internal failure costs related to the observed process

$\mathbf{i}, \mathbf{j}, \mathbf{k}$ - the same as described above, observed for the $\mathrm{x}_{\mathrm{z}}$ -th process within the $\mathrm{z}$-th case of impact

$\mathbf{N}_{\mathbf{z . x} \mathbf{x}_{\mathbf{z}}}$ - number of nonconforming cycles of $\mathrm{x}_{\mathbf{z}}$-th process of $\mathrm{z}$-th case of impact caused by $\mathrm{N}_{\mathrm{z}}$ nonconforming outputs of the observed process (initial in each its case of impact). This number can be determined through the number of final products that will be nonconforming as a consequence of $\mathrm{N}_{\mathrm{z}}$ nonconforming outputs of the observed process, in a way that $\mathrm{N}_{\mathrm{z} \cdot \mathrm{x}_{\mathrm{z}}}$ indicates a number of cycles of $\mathrm{x}_{\mathrm{z}}$-th process realization that is necessary for production of mentioned number of final products

If quality control points, as places of quality appraisal activities, are taken into consideration, then:

$\mathbf{i F}^{\prime} \mathbf{z x}_{\mathbf{z}} \cdot \mathbf{N}_{\mathbf{z}}$ - internal failure cost of the $\mathbf{x}_{\mathbf{z}}$-th process within the $z$-th case of impact that appears as a consequence of $\mathrm{N}_{\mathrm{Z}}$ nonconforming outputs from the observed process, when the nonconformities are detected in the $\mathrm{x}_{\mathrm{Z}}$-th process, which can be calculated as:

$$
\begin{aligned}
& \mathrm{iF}_{\mathrm{zx}_{\mathrm{z}} \cdot \mathrm{N}_{\mathrm{z}}}^{\prime}=\sum_{\mathrm{i}=1}^{\mathrm{I}} \mathrm{P}_{\mathrm{a}_{\mathrm{i}} \cdot \mathrm{zx}_{\mathrm{z}} \cdot \mathrm{N}_{\mathrm{z}}}+\sum_{\mathrm{j}=1}^{\mathrm{J}} \mathrm{A}_{\mathrm{a}_{\mathrm{j}} \cdot \mathrm{zx}_{\mathrm{z}} \cdot \mathrm{N}_{\mathrm{z}}}+\sum_{\mathrm{k}=1}^{\mathrm{K}} \mathrm{B}_{\mathrm{a}_{\mathrm{k}} \cdot \mathrm{zx}_{\mathrm{z}} \cdot \mathrm{N}_{\mathrm{z}}}+ \\
& +\sum_{\mathrm{h}=1}^{\mathrm{H}} \mathrm{iF}_{\mathrm{zx}_{\mathrm{z}} \cdot \mathrm{h} \cdot \mathrm{N}_{\mathrm{z}}}
\end{aligned}
$$

This equation is essentially the same as $\mathrm{iF}_{\mathrm{Zx}_{\mathrm{z}} \cdot \mathrm{N}_{\mathrm{z}}}$, with the difference that the costs of all the activities of the $\mathrm{P}, \mathrm{A}$ and $\mathrm{B}$ categories within the $\mathrm{x}_{\mathrm{z}}$-th process are not taken into account, but only those ending with the control point, where:

$\mathbf{i}=1, \ldots, \mathrm{KT}_{\mathrm{Zx}_{\mathrm{z}}}$ (includes those activities of the rows $1, \ldots \mathrm{KT}_{\mathrm{Zx}_{\mathrm{z}}}$ of $\mathrm{x}_{\mathrm{z}}$-th process that belong to $\mathrm{P}$ category)

$\mathbf{j}^{\prime}=1, \ldots, \mathrm{KT}_{\mathrm{Zx}_{\mathrm{z}}}$ (includes those activities of the rows $1, \ldots, \mathrm{KT}_{\mathrm{Zx}_{\mathrm{z}}}$ of $\mathrm{x}_{\mathrm{z}}$-th process that belong to A category)

$\mathbf{k}^{\prime}=1, \ldots, \mathrm{KT}_{\mathrm{Zx}_{\mathrm{z}}}$ (includes those activities of the rows $1, \ldots, \mathrm{KT}_{\mathrm{Zx}_{\mathrm{z}}}$ of $\mathrm{x}_{\mathrm{z}}$-th process that belong to $\mathrm{B}$ category)

$\mathbf{h}=1, \ldots, \mathrm{H}$ (the same as described above because indirect failure costs do not mean re-work so they are not related to the control points)

$\mathbf{K T}_{\mathbf{z x}} \mathbf{z}-$ control point of the $\mathrm{x}_{\mathrm{z}}$-th process within the $\mathrm{z}$ th case of impact

If the number of control points is more than one, than:

$\mathbf{K T y}_{\mathbf{z x}} \mathbf{z}_{\mathbf{z}}-\mathrm{y}$-th control point of the $\mathrm{x}_{\mathrm{z}}$-th process within the $\mathrm{z}$-th case of impact

$$
\mathrm{iF}_{\mathrm{zx}_{\mathrm{z}} \cdot \mathrm{N}_{\mathrm{z}}}^{,}=\sum_{\mathrm{y}=1}^{\mathrm{Y}} \mathrm{iF}_{\mathrm{zx}_{\mathrm{z}} \cdot \mathrm{N}_{\mathrm{z}} \cdot \mathrm{KTy}}^{\prime}+\sum_{\mathrm{h}=1}^{\mathrm{H}} \mathrm{iF}_{\mathrm{zx}_{\mathrm{z}} \cdot \mathrm{h} \cdot \mathrm{N}_{\mathrm{z}}}
$$

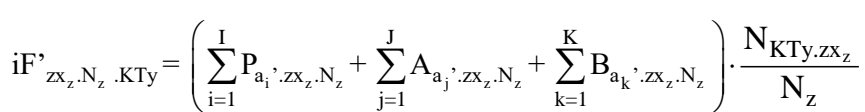

$\mathbf{Y}$ - number of control points

$\mathbf{i}^{\prime}=1, \ldots, \mathrm{KTy}_{\mathrm{zx}_{\mathrm{z}}}$ (includes those activities of the rows $1, \ldots, \mathrm{KTy}_{\mathrm{zx}_{\mathrm{z}}}$ of $\mathrm{x}_{\mathrm{z}}$-th process that belong to category $\mathrm{P}$ )

$\mathbf{j}^{\prime}=1, \ldots, \mathrm{KTy}_{\mathrm{zx}_{\mathrm{z}}}$ (includes those activities of the rows $1, \ldots, \mathrm{KTy}_{\mathrm{zx}_{\mathrm{z}}}$ of $\mathrm{x}_{\mathrm{z}}$-th process that belong to category $\mathrm{A}$ )

$\mathbf{k}^{\prime}=1, \ldots, \mathrm{KTy}_{\mathrm{zx}_{\mathrm{z}}}$ (includes those activities of the rows $1, \ldots, \mathrm{KTy}_{\mathrm{zx}_{\mathrm{z}}}$ of $\mathrm{x}_{\mathrm{z}}$-th process that belong to category $\mathrm{B}$ )

$\mathbf{N}_{\mathbf{K T y . z x}}$ - number of nonconforming outputs from the observed process, revealed in the y-th control point of the $\mathrm{x}_{\mathrm{z}}$-th process within the $\mathrm{z}$-th case of impact

When it comes to the external failure costs, then:

$\mathbf{e F}_{\mathbf{z U} \cdot \mathbf{N}_{\mathbf{z}}}$ are external failure costs of the observed process within the $\mathrm{z}$-th case of impact, for $\mathrm{N}_{\mathrm{z}}$ nonconforming outputs, when the nonconformities are revealed by a customer during the product usage. Like the costs of internal nonconformities, they consist of two subcategories:

$\mathrm{eF}_{\mathrm{zU} \cdot \mathrm{N}_{\mathrm{z}}}=$ direct $\mathrm{eF}$ costs + indirect $\mathrm{eF}$ costs

whereby the direct eF costs include activities for resolving nonconformities detected outside the system and, as such, often encompass customer complaints resolving, but they can be related to multiple stakeholders. The indirect $\mathrm{eF}$ costs are related to the consequences of such nonconformities. Therefore, for the z-th case of impact, external failure costs can be determined through:

$$
\mathrm{eF}_{\mathrm{zU} \cdot \mathrm{N}_{\mathrm{z}}}=\sum_{\mathrm{g}=1}^{\mathrm{G}} \mathrm{eF}\left(\mathrm{SH}_{\mathrm{zg}}\right)_{\cdot \mathrm{N}_{\mathrm{z}}}+\sum_{\mathrm{d}=1}^{\mathrm{D}} \mathrm{eF}_{\mathrm{zU} \cdot \mathrm{d} \cdot \mathrm{N}_{\mathrm{z}}}
$$

These costs can also be calculated using the number of nonconforming final products, as explained for costs of internal nonconformities, where $\mathrm{N}_{z . \mathrm{U}}$ is the number of nonconforming deliveries to the customer, caused by the occurrence of $\mathrm{N}_{\mathrm{z}}$ nonconforming cycles of the observed process. Therefore:

$$
\begin{aligned}
& \sum_{\mathrm{g}=1}^{\mathrm{G}} \mathrm{eF}\left(\mathrm{SH}_{\mathrm{zg}}\right)_{\mathrm{N}_{\mathrm{z}}}=\sum_{\mathrm{g}=1}^{\mathrm{G}} \mathrm{eF}\left(\mathrm{SH}_{\mathrm{zg}}\right) \cdot \mathrm{N}_{\mathrm{z} \cdot \mathrm{U}} \\
& \sum_{\mathrm{d}=1}^{\mathrm{D}} \mathrm{eF}_{\mathrm{zU} \cdot \mathrm{d} \cdot \mathrm{N}_{\mathrm{z}}}=\sum_{\mathrm{d}=1}^{\mathrm{D}} \mathrm{eF}_{\mathrm{zU} \cdot \mathrm{d}} \cdot \mathrm{N}_{\mathrm{z} . \mathrm{U}}
\end{aligned}
$$

G - number of stakeholders that are affected by nonconforming outputs from the organizational system

$\mathbf{S H}_{\mathbf{z g}}-\mathrm{g}$-th stakeholder in the z-th case of impact

$\mathbf{e F}\left(\mathbf{S H}_{\mathbf{z g}}\right)$ - the cost of solving one nonconforming delivery of final products which affected the g-th stakeholder, in z-th case of impact

$\mathbf{e F}\left(\mathbf{S H}_{\mathrm{zg}}\right)_{\mathbf{N}_{\mathbf{z}}}-$ costs of solving all the nonconforming deliveries of final products caused by $\mathrm{N}_{\mathrm{z}}$ nonconforming 
outputs from the observed process, which affected the g-th stakeholder, in z-th case of impact

D - number of indirect external failure costs

$\mathbf{e F}_{\mathbf{z U} . \mathbf{d}}-\mathrm{d}$-th indirect external failure cost for one delivery of final products to customer, in z-th case of impact

$\mathbf{e F}_{\mathbf{z U} \cdot \mathbf{d} \cdot \mathbf{N}_{\mathbf{z}}}-$ d-th indirect external failure cost caused by $\mathrm{N}_{\mathrm{z}}$ nonconforming outputs of the observed process, in z-th case of impact

$\mathbf{N}_{\mathbf{z} . \mathbf{U}}$ - number of nonconforming deliveries to the customer as a consequence of $\mathrm{N}_{\mathrm{z}}$ nonconforming outputs of the observed process

Subliming all the above elements of the quality costs for the z-th case of impact, two cases of number of nonconforming outputs are possible:

If $\mathrm{Nz}=0: \mathrm{F}_{\mathrm{z} \cdot \mathrm{N}_{\mathrm{z}}}=0$

If $\mathrm{NZ}>0$ :

$$
\begin{aligned}
& \mathrm{F}_{\mathrm{z} \cdot \mathrm{N}_{\mathrm{z}}}=\mathrm{iF}^{\prime}{ }_{\mathrm{z} 0 . \mathrm{N}_{\mathrm{z}}} \cdot \frac{\mathrm{N}_{\mathrm{z} 0}}{\mathrm{~N}_{\mathrm{z}}}+\left(\mathrm{iF}_{\mathrm{z} 0 . \mathrm{N}_{\mathrm{z}}}+\mathrm{iF}^{\prime}{ }_{\mathrm{z} 1 \cdot \mathrm{N}_{\mathrm{z}}}\right) \cdot \frac{\mathrm{N}_{\mathrm{z} 1}}{\mathrm{~N}_{\mathrm{z}}}+\ldots+ \\
& +\left(\mathrm{iF}_{\mathrm{z} 0 . \mathrm{N}_{\mathrm{z}}}+\mathrm{iF}_{\mathrm{z} 1 \cdot \mathrm{N}_{\mathrm{z}}}+\ldots+\mathrm{iF}_{\left.\mathrm{zX}_{\mathrm{z} \cdot \mathrm{N}_{\mathrm{z}}}\right)}\right) \cdot \frac{\mathrm{N}_{\mathrm{zX} \mathrm{z}}}{\mathrm{N}_{\mathrm{z}}}+ \\
& +\left(\mathrm{iF}_{\mathrm{z} 0 . \mathrm{N}_{\mathrm{z}}}+\mathrm{iF}_{\mathrm{z} 1 \cdot \mathrm{N}_{\mathrm{z}}}+\ldots+\mathrm{iF}_{\mathrm{zX}_{\mathrm{z}} \cdot \mathrm{N}_{\mathrm{z}}}+\mathrm{eF}_{\mathrm{zU} \cdot \mathrm{N}_{\mathrm{z}}}\right) \cdot \frac{\mathrm{N}_{\mathrm{zU}}}{\mathrm{N}_{\mathrm{z}}}
\end{aligned}
$$

Thus, quality costs of the process within the given period of time are:

$$
\mathrm{CoQ}=\mathrm{P}_{\mathrm{M}}+\mathrm{A}_{\mathrm{M}}+\sum_{\mathrm{z}=1}^{\mathrm{Z}} \mathrm{F}_{\mathrm{z} \cdot \mathrm{N}_{\mathrm{z}}}
$$

Further, taking into the consideration previously analyzed equation (19) for failure cost for the observed case of impact and including it in equation (20), quality costs of observed process encompass:

$$
\begin{aligned}
& \mathrm{CoQ}_{\text {process name }}=\sum_{\mathrm{i}=1}^{\mathrm{I}} \mathrm{P}_{\mathrm{a}_{\mathrm{i}} \cdot \mathrm{M}}+\sum_{\mathrm{j}=1}^{\mathrm{J}} \mathrm{A}_{\mathrm{a}_{\mathrm{j}} \cdot \mathrm{M}}+ \\
& +\sum_{\mathrm{z}=1}^{\mathrm{Z}}\left[\mathrm{iF}_{\mathrm{z} 0 \cdot \mathrm{N}_{\mathrm{z}}} \cdot \frac{\mathrm{N}_{\mathrm{z} 0}}{\mathrm{~N}_{\mathrm{z}}}+\left(\mathrm{iF}_{\mathrm{z} 0 \cdot \mathrm{N}_{\mathrm{z}}}+\mathrm{iF}_{\mathrm{z} 1 \cdot \mathrm{N}_{\mathrm{z}}}\right) \cdot \frac{\mathrm{N}_{\mathrm{z} 1}}{\mathrm{~N}_{\mathrm{z}}}+\ldots\right. \\
& +\left(\mathrm{iF}_{\mathrm{z} 0 \cdot \mathrm{N}_{\mathrm{z}}}+\mathrm{iF}_{\mathrm{z} 1 \cdot \mathrm{N}_{\mathrm{z}}}+\ldots+\mathrm{iF}_{\mathrm{zX} \cdot \mathrm{N}_{\mathrm{z}}}^{\prime}\right) \cdot \frac{\mathrm{N}_{\mathrm{zX}}}{\mathrm{N}_{\mathrm{z}}}+ \\
& \left.+\left(\mathrm{iF}_{\mathrm{z} 0 . \mathrm{N}_{\mathrm{z}}}+\mathrm{iF}_{\mathrm{z} 1 \cdot \mathrm{N}_{\mathrm{z}}}+\ldots+\mathrm{iF}_{\mathrm{zX} \mathrm{z} \cdot \mathrm{N}_{\mathrm{z}}}+\mathrm{eF}_{\mathrm{zU} \cdot \mathrm{N}_{\mathrm{z}}}\right) \cdot \frac{\mathrm{N}_{\mathrm{zU}}}{\mathrm{N}_{\mathrm{z}}}\right]
\end{aligned}
$$

Using these equations, it is possible to calculate total quality costs of observed process in the following two moments: $t_{0}$ and $t_{1}$.

CoQ process name $\left(t_{0}\right)$ - real current quality costs of the observed process in the moment $t_{0}$ (before improvements)

CoQ process name $\left(\mathbf{t}_{1}\right)$ - expected future quality costs of the observed process in the moment $t_{1}$ (after improvements)

1. Analysing causes of nonconformities: To assume the expected costs in the moment $t_{1}$ (after improvements) it is necessary to analyze the causes of nonconformities (real and potential) and their frequency in each case of impact (Table 4).

Table 4

Data on the Causes of Nonconformities

\begin{tabular}{|l|c|c|c|c|}
\hline Causes & $\begin{array}{c}\text { Case of } \\
\text { impact: } \mathbf{I}_{\mathbf{1}}\end{array}$ & $\begin{array}{c}\text { Case of } \\
\text { impact: } \mathbf{I}_{\mathbf{2}}\end{array}$ & $\ldots \mathbf{I}_{\mathbf{z}} \ldots$ & $\begin{array}{c}\text { Case of } \\
\text { impact: } \mathbf{I}_{\mathbf{Z}}\end{array}$ \\
\hline Cause 1 & $\mathrm{U}_{11}$ & $\mathrm{U}_{21}$ & & $\mathrm{U}_{\mathrm{Z} 1}$ \\
\hline Cause 2 & $\mathrm{U}_{12}$ & $\mathrm{U}_{22}$ & & $\mathrm{U}_{\mathrm{Z} 2}$ \\
\hline$\ldots$ & & & & \\
\hline Cause C & $\mathrm{U}_{1 \mathrm{C}}$ & $\mathrm{U}_{2 \mathrm{C}}$ & & $\mathrm{U}_{\mathrm{ZC}}$ \\
\hline \multicolumn{5}{|c}{$U_{z c}-$ the frequency of $c$-th cause in $z$-th case of impact }
\end{tabular}

4. Defining necessary measures: On the basis of nonconformities analysis, it is possible to conclude: which preventive activities will lead to a reduction in the number of nonconforming outputs if included/improved; and which appraisal activities will lead to an increase in the number of nonconforming outputs detected on time if included/improved.

Data on the causes of nonconformities (Table 4) may be used in the following way: e.g. if there are 5 nonconforming outputs from the process and if 4 of them are because of inadequate planning, the proposition is that after improvement of planning as a preventive activity, those 4 nonconforming outputs should disappear. If e.g. 1 of the nonconforming outputs is caused by unintentional failure, it could appear in the moment $t_{1}$ too, because of which an adequate appraisal activity is required.

So, based on such nonconformity analysis, an adequate preventive and/or appraisal activities should be recognized and taken aiming at reduction of nonconformity effect and/or probability to happen.

5. Determining effects of measures: Taking previously defined measures means that some preventive and appraisal activities should be improved or include new activities, so their costs should probably increase. But, consequently the number of nonconformities is expected to significantly decrease as a result of which the failure costs should be lower. Therefore, steps 1.1. -1.4. should be taken again for the case of the moment $t_{1}$ (after the suggested improvement). The result should be less influence on other processes and thus lower total failure costs, reducing the total quality costs to the minimum.

6. Re-determining costs of quality: Taking the effects of previously defined measures into account, and using equations given in step 2, the expected quality costs in the moment $t_{1}$, denoted as CoQ process name $\left(t_{1}\right)$, should be estimated.

7. Analysing costs of quality and decision making: Using the calculated values of CoQ in the two mentioned moments:

$$
\Delta \mathrm{CoQ} \text { process name }=\mathrm{CoQ}_{\text {process name }}\left(\mathrm{t}_{0}\right) \text { - }
$$$$
\text { - CoQ process name }\left(\mathrm{t}_{1}\right)
$$

$\Delta \mathrm{CoQ}$ process name - difference between the actual current and expected future quality costs, observing the same period of time

$\triangle \mathrm{CoQ}$ can be used as criteria for process ranking according to the priority for improvement, where a higher 
$\Delta \mathrm{CoQ}$ value, as the greater possible reduction of quality costs of the process, indicates its higher priority for taking defined measures. This enables the comparison of quality costs variants, where a variant can include improvement of one process, or combinations of processes.

Necessary investment (Inv) for carrying out the required improvement of the process is included in the $\Delta \mathrm{CoQ}$ value, but it can also be determined by:

$$
\begin{aligned}
& \text { Inv process name }=\sum_{\mathrm{i}=1}^{\mathrm{I}} \mathrm{P}_{\mathrm{a}_{\mathrm{i}} \cdot \mathrm{M}}\left(\mathrm{t}_{1}\right)-\sum_{\mathrm{i}=1}^{\mathrm{I}} \mathrm{P}_{\mathrm{a}_{\mathrm{i}} \cdot \mathrm{M}}\left(\mathrm{t}_{0}\right)+ \\
& +\sum_{\mathrm{j}=1}^{\mathrm{J}} \mathrm{A}_{\mathrm{a}_{\mathrm{j}} \cdot \mathrm{M}}\left(\mathrm{t}_{1}\right)-\sum_{\mathrm{j}=1}^{\mathrm{J}} \mathrm{A}_{\mathrm{a}_{\mathrm{j}} \cdot \mathrm{M}}\left(\mathrm{t}_{0}\right)
\end{aligned}
$$

Necessary investment can be important data if there are limitations in the amount of money for the improvements. This amount is a cost in the form of an initial investment in order to achieve long-term reduction in the total quality costs.

All the values of calculated quality costs are compared to a percentage of the total current quality costs as reference values, aiming at observing them as relative, mutually comparable values.

\section{Model Application Example}

Since the case study approach is a useful strategy to answer the questions formulated in the research, Yin (2013) methodology was used with four steps: design the case, conduct the case, analyse the case evidence and develop conclusions. Taking into account a trend to apply quality cost models in both manufacturing and servicebased companies, the case study is conducted in the company based on the furniture production, which includes service of making and selling furniture according to the specific customers' requirements. The units of analysis were quality costs related to the wooden piece furniture through the two main processes of production (production of wooden structures and production of upholstered pieces), as well as sales and procurement processes.

Methods used for data collecting about the processes and their interdependencies, their costs, as well as data about nonconformance analysis are interviewing process owners and the company's documentation review, including procedures, reports invoices, the customer list and other records.

Findings about the quality costs are interpreted in monetary units and compared to the percentage of the total current quality costs, as the reference value. Observing the quality costs as mutually comparable values enables obtaining conclusions about different quality costs variants.

A company for wooden furniture production, which produces about $\mathrm{FP}=1200$ pieces a year, divided into $\mathrm{D}=30$ deliveries, that is delivered to $\mathrm{W}=60$ customers on average, is considered.

This study observed four processes: sales, production 1 (production of wooden structures), production 2 (production of upholstered pieces), and procurement. Considering that the financial constraints for investment within the company amount to $€ 2000$, the quality costs analysis showed five possible options for improvement: option 1 includes improvement of the sales process, option 2 includes improvement of the production 1 process, option 3 includes improvement of the production 2 process, option 4 includes improvement of the procurement process, option 5 includes simultaneous improvement of the sales and production 2 processes. The values of quality costs for each option are given in Table 5, while their graphics presentation is given in Figure 3.

\begin{tabular}{|c|c|c|c|c|c|c|c|c|c|c|c|}
\hline & & \multicolumn{2}{|c|}{ Option 1} & \multicolumn{2}{|c|}{ Option 2} & \multicolumn{2}{|c|}{ Option 3} & \multicolumn{2}{|c|}{ Option 4} & \multicolumn{2}{|c|}{ Option 5} \\
\hline & CoQt0 & CoQt1 & $\Delta \mathrm{CoQ}$ & CoQt1 & $\Delta \mathrm{CoQ}$ & CoQt1 & $\Delta \mathrm{CoQ}$ & CoQt1 & $\Delta \mathrm{CoQ}$ & CoQt1 & $\Delta \mathrm{CoQ}$ \\
\hline Sale & 6266 & 6192 & 74 & 6266 & 0 & 6266 & 0 & 6266 & 0 & 6192 & 74 \\
\hline Production 1 & 9254 & 9258 & -4 & 4117 & 5137 & 9254 & 0 & 9254 & 0 & 9258 & -4 \\
\hline Production 2 & 4336 & 4338 & -2 & 4336 & 0 & 1804 & 2532 & 4336 & 0 & 1804 & 2532 \\
\hline Purchase & 12234 & 12239 & -5 & 12293 & -59 & 12255 & -22 & 4171 & 8063 & 12261 & -27 \\
\hline$\sum(€)$ & 32089 & 32026 & 63 & 27012 & 5077 & 29579 & 2510 & 24026 & 8063 & 29514 & 2575 \\
\hline$\%$ & $\mathbf{0 , 5 3}$ & 1,00 & $\mathbf{0 , 0 0}$ & 0,84 & 0,16 & 0,92 & $\mathbf{0 , 0 8}$ & 0,75 & 0,25 & 0,92 & $\mathbf{0 , 0 8}$ \\
\hline \multicolumn{2}{|c|}{ Investment } & \multicolumn{2}{|c|}{ Option 1} & \multicolumn{2}{|c|}{ Option 2} & \multicolumn{2}{|c|}{ Option 3} & \multicolumn{2}{|c|}{ Option 4} & \multicolumn{2}{|c|}{ Option 5} \\
\hline & $\sum(€)$ & & 120 & & 1960 & & 720 & & 1071 & & 840 \\
\hline & $\%$ & & 0,00374 & & 0,06108 & & 0,02244 & & 0,03338 & & 0,0262 \\
\hline \multicolumn{2}{|c|}{ The ratio of $\Delta \mathrm{CoQ}$ and inv. } & \multicolumn{2}{|c|}{ Option 1} & \multicolumn{2}{|c|}{ Option 2} & \multicolumn{2}{|c|}{ Option 3} & \multicolumn{2}{|c|}{ Option 4} & \multicolumn{2}{|c|}{ Option 5} \\
\hline & $\%$ & \multicolumn{2}{|c|}{0,52167} & \multicolumn{2}{|c|}{2,59044} & \multicolumn{2}{|c|}{3,48644} & \multicolumn{2}{|c|}{7,52824} & \multicolumn{2}{|c|}{3,0653} \\
\hline
\end{tabular}

Options for Improvement based on Quality cost Analysis by Processes 

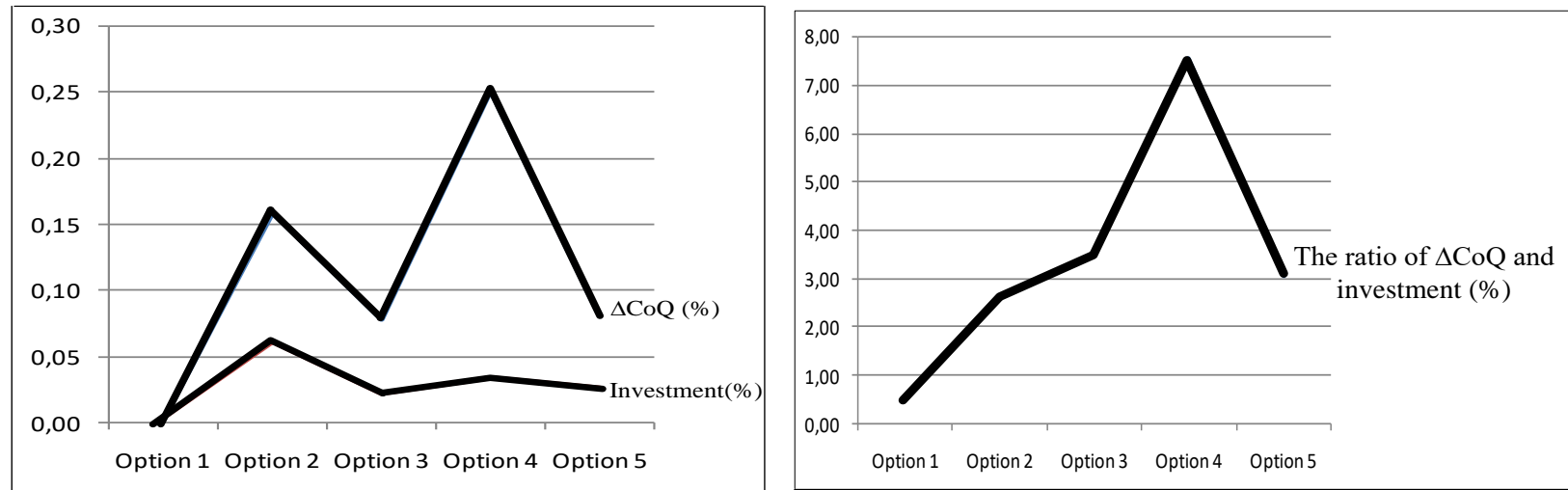

Figure 3. Data on the Values of Quality Costs and the Necessary Investments by Options

Given that option 4 stood out as optimal, an example of calculating the quality cost will be given for the process of procuring material resources. Before the improvements, this process consisted of the following activities:

Table 6

\section{Data on the Process before Improvements}

\begin{tabular}{|l|l|c|c|c|}
\hline $\mathbf{N}_{\mathbf{0}}$ & Activities & $\begin{array}{c}\mathbf{P} \\
(\boldsymbol{\epsilon})\end{array}$ & $\begin{array}{c}\mathbf{A} \\
(\boldsymbol{\epsilon})\end{array}$ & $\begin{array}{c}\text { B } \\
(\boldsymbol{\epsilon})\end{array}$ \\
\hline 1. & Inventory planning and monitoring & 16 & & \\
\hline 2. & Processing requests for procurement & 18 & & \\
\hline 3. & Selection of suppliers & & & 14 \\
\hline 4. & Ordering & & & 14 \\
\hline 5. & Transporting & & & 32 \\
\hline 6. & Receipt of goods & & 28 \\
\hline 7. & Admission control of goods & & 23 & \\
\hline 8. & Storage & & & 27 \\
\hline 9. & Issuance of goods from storage & & 18 \\
\hline
\end{tabular}

After collecting data on the cases of impact of this process and the outputs from the process, including nonconforming outputs, the equations from step 2 in the method were used:

$$
\begin{gathered}
\mathrm{F}_{\mathrm{z} \cdot \mathrm{N}_{\mathrm{z}}}=\mathrm{iF}_{\mathrm{z} 0 . \mathrm{N}_{\mathrm{z}}}^{\prime} \cdot \frac{\mathrm{N}_{\mathrm{z} 0}}{\mathrm{~N}_{\mathrm{z}}}+\left(\mathrm{iF}_{\mathrm{z} 0 . \mathrm{N}_{\mathrm{z}}}+\mathrm{iF}^{\prime}{ }_{\mathrm{z} 1 \cdot \mathrm{N}_{\mathrm{z}}}\right) \cdot \frac{\mathrm{N}_{\mathrm{zl}}}{\mathrm{N}_{\mathrm{z}}}+\ldots+ \\
+\left(\mathrm{iF}_{\mathrm{z} 0 . \mathrm{N}_{\mathrm{z}}}+\mathrm{iF}_{\mathrm{z} 1 . \mathrm{N}_{\mathrm{z}}}+\ldots+\mathrm{iF}_{\mathrm{zX} \mathrm{z} \cdot \mathrm{N}_{\mathrm{z}}}^{\prime}\right) \cdot \frac{\mathrm{N}_{\mathrm{zX}}}{\mathrm{N}_{\mathrm{z}}}+ \\
+\left(\mathrm{iF}_{\mathrm{z} 0 . \mathrm{N}_{\mathrm{z}}}+\mathrm{iF}_{\mathrm{z} 1 \cdot \mathrm{N}_{\mathrm{z}}}+\ldots+\mathrm{iF}_{\mathrm{zX} \mathrm{z} \cdot \mathrm{N}_{\mathrm{z}}}+\mathrm{eF}_{\mathrm{zU} \cdot \mathrm{N}_{\mathrm{z}}}\right) \cdot \frac{\mathrm{N}_{\mathrm{zU}}}{\mathrm{N}_{\mathrm{z}}}
\end{gathered}
$$

resulting in a calculation that failure quality costs of the process of procurement in moment $t_{0}$ for each case of impact separately amount to:

- For case $\mathrm{I}_{1}$ : 1.0 Procurement - 1.1 Production (of wooden structures) - $1 \mathrm{U}$ Product usage, $\mathrm{F}_{1 . \mathrm{N} 1}=4796$;

- For case $\mathrm{I}_{2}$ : 1.0 Procurement - 1.1 Production (of upholstered pieces) - $1 \mathrm{U}$ Product usage, $\mathrm{F}_{2 . \mathrm{N} 2}=0$;

- For case $\mathrm{I}_{3}$ : 1.0 Procurement - 1.1 Production (of both wooden structures and upholstered pieces) - 1U Product usage, $\mathrm{F}_{3 . \mathrm{N} 3}=4531$;

- For case $\mathrm{I}_{4}$ : 1.0 Procurement - 1.1 All the processes $1 \mathrm{U}$ Product usage, $\mathrm{F}_{4 . \mathrm{N} 4}=0$

Quality costs of the process of procurement in the moment before improvements $\left(\mathrm{t}_{0}\right)$, for a one year period, are:

$$
\begin{gathered}
\operatorname{CoQ}_{\text {procurement }}\left(t_{\mathbf{0}}\right)=\mathrm{P}_{\mathrm{M}}+\mathrm{A}_{\mathrm{M}}+\sum_{\mathrm{z}=1}^{\mathrm{Z}} \mathrm{F}_{\mathrm{z} . \mathrm{N}_{\mathrm{z}}} \\
\operatorname{CoQ} \text { procurement }\left(\mathrm{t}_{\mathbf{0}}\right)=\mathbf{1 7 3 4}+\mathbf{1 1 7 3}+\mathbf{9 3 2 7}=\mathbf{1 2 2 3 4 €}
\end{gathered}
$$

Data on the causes of nonconformities showed that the key causes of nonconformities and their frequency are the following:

- Inadequate selection of suppliers - 2 nonconformities in the observed period of time,

- Inadequate (oral) ordering - 2 nonconformities in the observed period of time,

- Coincidental failures (during transporting) - 1 nonconformity in the observed period of time.

After analysis of the causes of nonconformities, there was a suggestion to add specific preventive activities within this process, as shown in Table 7.

Quality costs of the process of procurement in the moment after improvements $\left(t_{1}\right)$, for a one year period are:

$$
\operatorname{CoQ}_{\text {procurement }}\left(\mathbf{t}_{1}\right)=\mathrm{P}_{\mathrm{M}}+\mathrm{A}_{\mathrm{M}}+\sum_{\mathrm{z}=1}^{\mathrm{Z}} \mathrm{F}_{\mathrm{z} . \mathrm{N}_{\mathrm{z}}}
$$

CoQ procurement $\left(t_{1}\right)=3060+918+193=4171 €$

Now, potential reduction of quality costs for this process can be expressed as:

$$
\begin{aligned}
\Delta \mathrm{CoQ}_{\text {procurement }}= & \mathrm{CoQ} \text { procurement }\left(\mathrm{t}_{\mathbf{0}}\right)-\mathrm{Co} \mathrm{Q}_{\text {procurement }}\left(\mathrm{t}_{1}\right)= \\
& 12234-4171=8063 €
\end{aligned}
$$

Table 7

Data on the Process after Improvements

\begin{tabular}{|c|l|c|c|c|}
\hline $\mathbf{N}_{\mathbf{0}}$ & Activities & $\mathbf{P}(\boldsymbol{\epsilon})$ & $\mathbf{A}(\boldsymbol{\epsilon})$ & $\mathbf{B}(\boldsymbol{\epsilon})$ \\
\hline 1. & Inventory planning and monitoring & 16 & & \\
\hline 2. & Processing requests for procurement & 18 & & \\
\hline 3. & Evaluation of suppliers * & 12 & & \\
\hline 4. & Selection of suppliers & & & 14 \\
\hline 5. & Creating a written purchase order* & 14 & & \\
\hline 6. & Ordering & & & 14 \\
\hline 7. & Transporting & & & 32 \\
\hline 8. & Receipt of goods & & & 28 \\
\hline 9. & Admission control of goods & & & \\
\hline 10. & Storage & & & 27 \\
\hline 11. & Issuance of goods from storage & & 18 \\
\hline
\end{tabular}

* Preventive and appraisal activities, implemented or improved in the moment $\mathrm{t}_{1}$ 
This reduction can be achieved with the investment:

$$
\begin{gathered}
\text { Inv procurement }=\sum_{i=1}^{I} P_{a_{i} \cdot M}\left(t_{1}\right)-\sum_{i=1}^{I} P_{a_{i} \cdot M}\left(t_{0}\right)+ \\
+\sum_{j=1}^{J} A_{a_{j} \cdot M}\left(t_{1}\right)-\sum_{j=1}^{J} A_{a_{j} \cdot M}\left(t_{0}\right)
\end{gathered}
$$

Inv procurement $=3060+918-1734-1173=1071 €$

A parallel view of quality costs (by PAF categories and overall) for the procurement process before improvements $\left(t_{0}\right)$ and after improvements $\left(t_{1}\right)$ is shown in Figure 4.

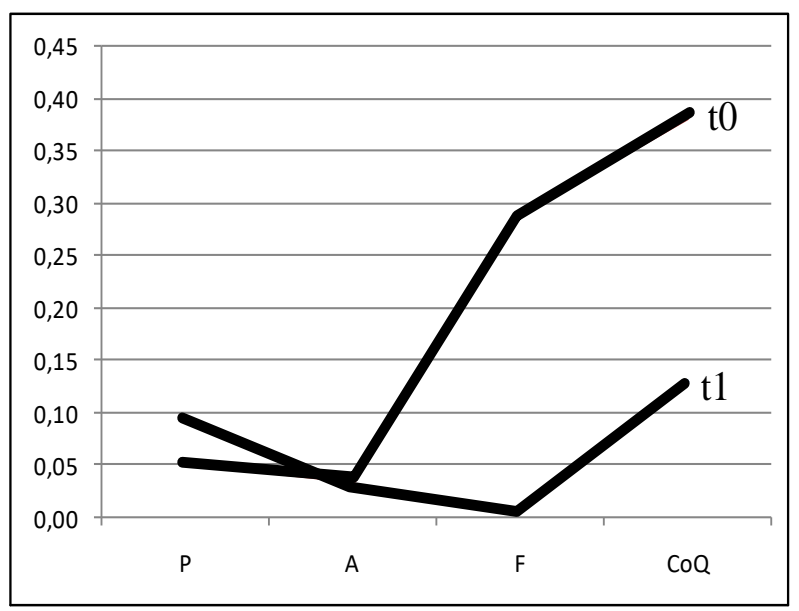

Figure 4. Values of Quality Costs for the Process of Procurement before and After Improvements

\section{Experts Evaluation of the Model}

All of the 50 experts included in the model evaluation have at least the educational degree of quality management engineer. They have years of working experience in quality management practice in different, both manufacturing and service-based companies, from various countries (within Europe, SAD, Canada, Russia and China) operating on Serbian, Europian or worldwide market. All of them see quality costing as an important field of practice.

The experts responded to the 23 questions by marking one of 5 possible answers: 1-Completely disagree; 2Disagree; 3-Partly agree; 4-Agree; 5-Completely agree. The expert evaluation also included an interview with five quality management experts who have significant experience in the field of quality costs and theoretical experience gained by publishing books and papers on this topic, as well as practical experience gained by participating in the implementation and maintenance of quality costs systems in various companies.

The average score of experts' evaluation of the proposed model, according to each model characteristic is given in Table 8. Results show that none of the questions have a negative average score (less than a half of the maximum score). The total average score of the model for all questions, that is, for all experts is Mean=4,174, with $\mathrm{SDT}=0,778$, which is a very good, bordering on excellent, final score for the model.

After subliming and analyzing all the experts' suggestions and observations, including those given through the interview with the eminent Ph.D. quality experts, some changes are made in the model.

Table 8

\begin{tabular}{|c|c|c|}
\hline Questions for evaluation of the model & Mean & STD \\
\hline $\begin{array}{l}\text { Does the model enable an adequate identification of } \\
\text { quality costs? }\end{array}$ & 4,612 & 0,571 \\
\hline $\begin{array}{l}\text { Does the model enable an adequate categorization } \\
\text { of quality costs (PAF)? }\end{array}$ & 4,490 & 0,616 \\
\hline $\begin{array}{l}\text { Does the model enable an adequate linking quality } \\
\text { costs to processes? }\end{array}$ & 4,52 & 0,580 \\
\hline $\begin{array}{l}\text { Is the idea of a model that the quality cost of a } \\
\text { process affects the quality costs of other processes } \\
\text { meaningful? }\end{array}$ & 4,62 & 0,697 \\
\hline $\begin{array}{l}\text { Does the model observe adequately the impact of } \\
\text { the quality costs of a process on the quality costs of } \\
\text { other processes in the system? }\end{array}$ & 4,44 & 0,644 \\
\hline $\begin{array}{l}\text { Does the model include a sufficiently } \\
\text { comprehensive analysis of quality costs? }\end{array}$ & 4,333 & 0,834 \\
\hline Can the model be continuously applied? & 4,34 & 0,823 \\
\hline Is it simply to use the model? & 3,68 & 1,019 \\
\hline $\begin{array}{l}\text { Does the model have many real problems for } \\
\text { application? }\end{array}$ & 2,68 & 1,019 \\
\hline $\begin{array}{l}\text { Is it simply to get to the data about nonconformities } \\
\text { in the system? }\end{array}$ & 3,24 & 1,041 \\
\hline $\begin{array}{l}\text { Is it simply to get to the data about quality costs of } \\
\text { activities? }\end{array}$ & 3,44 & 1,013 \\
\hline $\begin{array}{l}\text { Is it easier to use the model after the first } \\
\text { implementation, by changing the required data? }\end{array}$ & 4,286 & 0,764 \\
\hline $\begin{array}{l}\text { Is the model's focused on the reduction of the total } \\
\text { quality costs? }\end{array}$ & 4,48 & 0,735 \\
\hline $\begin{array}{l}\text { Does the model enable the comparison of different } \\
\text { quality costs variants? }\end{array}$ & 4,24 & 0,847 \\
\hline $\begin{array}{l}\text { Does the model provide a basis for making } \\
\text { decisions about improvement? }\end{array}$ & 4,46 & 0,734 \\
\hline Does the model support the TQM concept? & 4,54 & 0,645 \\
\hline $\begin{array}{l}\text { Can the model be applied in various scopes so that } \\
\text { it suits the needs of a specific organization? }\end{array}$ & 4,54 & 0,645 \\
\hline Is the model useful in practice? & 4,4 & 0,756 \\
\hline $\begin{array}{l}\text { Does the model have better performance compared } \\
\text { to traditional quality costs models? }\end{array}$ & 3,958 & 0,798 \\
\hline $\begin{array}{l}\text { Can the model give an useful input data into some } \\
\text { other methods such as FMEA, QFD, Cost-Benefit... }\end{array}$ & 4,367 & 0,727 \\
\hline AVERAGE & 4,174 & 0,778 \\
\hline
\end{tabular}

Evaluation of the Model

Majority of the experts (72\%) pointed out that they would apply the model in their companies, while the rest of them have no clear attitude about that. The evaluation also included questions about what limitations would they expect during the model application and about their suggestions for improving the model. Those issues are discussed within the conclusions and discussions of the paper.

\section{Conclusions and Discussions}

One of the important principles of quality management is to minimize the total quality costs (Mizla \& Pudlo, 2012) as a significant quality level indicator. Conclusions from the pre-research (Glogovac \& Filipovic, 2017) indicate that the companies perceive the following factors to be key advantages of quality costing practice: improvement in quality, reduction of total costs, the ability to improve the company's development planning, monitoring the costeffectiveness of the quality management programs and measures, reduction of the activities with constant mistakes, reduction of waste, reduction of excessive use of resources, ability of failure analysis, ability to predict 
various outcomes, problematic spots through which the money is spent become visible and clear, defining new goals and programs to improve the company's work, the motivation and enthusiasm of employees is raised in the company by successful resolution/reduction of poor quality costs, and the provision of data necessary for the adoption of appropriate decisions regarding improvements. All of the above, as respondents point out, contributes to increased competitiveness and greater customer satisfaction, which they perceive as their ultimate goal. Furthermore, CoQ can be viewed as a substitute for many other inputs into the review of a QMS. In line with this, performance evaluation can be analyzed on the basis of the CoQ data.

Although the PAF is the most systematic and logical quality cost model, it is designed to be used at the level of the whole organizational system. On the other hand, some general quality management assumptions point to the importance of process management. Applying quality cost programs on the process level could enable to identify processes that generate the highest quality cost as the important places for improvement. Although there is the Process cost model, it doesn't make a difference among the PAF categories. Making such difference is important since the category of cost indicate its behavior and possible influence on other cost categories.

In line with this, as well as the importance of process management for quality improvements, the PAF model is used in this paper on the level of processes in order to identify processes that generate the highest quality costs and hence indicate the highest ranked improvement opportunity. According to the process-systemic approach regarding processes interdependences, the basic idea of this model was that the quality costs of one process should not be considered only in regard to the process itself, but they also should be related to the processes that use the outputs from the observed process as their inputs. This happens due to nonconformities from the observed processes that are not revealed within it, but go further into the other processes generating more nonconformities. So, the later the nonconformities are detected in the processes, that is, the closer they are to the product usage by the customer, the greater the costs of such nonconformities will be. This consideration is important because it was found that the costs of nonconformities are the key category of quality costs as they provide the opportunity for the greatest reduction in total costs since they participate in the total quality costs significantly more than other categories. That is why the failure costs of a process should not be considered only in regard to that process, since nonconformities occurring in one process can affect others through its outputs. Therefore, the data on locations where nonconformities were detected support the calculation of the process quality cost. The nonconformities analysis in this model also includes data on their causes, which are used to make decisions about the selection of the adequate preventive or appraisal activities, which should be improved in order to reduce total costs. It is possible to invest inadequately in these activities so that a significant influence on the reduction of total costs is not achieved, which is why the decision about this kind of improvement should be made based on the analysis of the causes of nonconformities. This makes it possible to determine, in addition to the current process quality costs, the expected costs which would result from the improvement. It is then possible to compare different variants of improvement, based on the difference between total quality costs in two observed moments, as values of the highest possible reduction in the total process quality costs (considered in relation to the reference value to enable quality cost variants comparability). They can be related to individual processes, but also to the improvement of multiple processes, within one variant.

In this way, the proposed model becomes a practical tool for the comparison of different quality costs variants within an organizational system, which could be achieved in the observed time by implementing the required improvements related to the inclusion of new and/or improvement of existing preventive and appraisal activities. This further lead to a reduction in a number of nonconforming outputs, and therefore a reduction in the failure process cost, as well as the processes it influences by its outputs.

The proposed method is based on the idea of PAF model that minimal quality cost is reached when the quality level is the highest. Thus, the proposed CoQ model can be applied through multiple improvement iterations, until the maximum quality is reached, and therefore the minimum costs accompanying the low quality too, within the limitations of the budget and current level of technology.

Application of the proposed model in the real production company enabled comparability of different variants of the quality cost that require various quality improvement alternatives. It can be seen from the Figure 3 that the improvement of the process of procurement is the improvement opportunity with the best ratio between reduction in total quality cost and necessary investment in improvement. Such model results make it possible to rank the improvement opportunities according to the quality cost level of observed processes, as an important indicator of their quality, as well as according to the cause of nonconformity analysis. By the model application, important conclusions about the research questions are drawn. It is concluded that the process-systemic approach according to which one process could affect the quality of others by its outputs can be used as a basis for modeling quality cost. It is also concluded that application of quality cost model based on the process-systemic approach and process interdependency enables to calculate quality costs of processes, considered in relation to the total quality cost as the referent value. Further, such data make it possible to compare and rank different variants of the quality cost, as different quality improvement opportunities.

When it comes to the limitation of the model application in the practice, the pre-research (Glogovac \& Filipovic, 2017) has found that the companies that do not apply the practice of CoQ management mostly have as their reason a lack of time and other resources, as well as a lack of interest from the company's top management. Those are mainly companies with the lower level of QMS maturity. Also, time spent on required nonconformity analysis can be seen as a significant limitation of the method. An important condition for the model application is that the company is prone to the risk-based thinking and 
has, or tends to have well developed QMS. While evaluating the model, a significant number of quality management experts pointed out employee resistance towards accepting new methods as potential obstacles for the model application in their companies. Since the comprehensive process analysis is required for the model, unstable environment, where processes and their context change much, could also be seen as a possible limitation. In order to partly overcome some of those limitations, the model does not need to be performed for the entire organizational system, but only for specific processes, if the company identifies several processes as potentially critical according to the quality. It also does not need to be applied continuously, but just in a specific period of times,

\section{References}

Abdul-Kader, W., Ganjavi, O., \& Solaiman, A. (2010). An integrated model for optimisation of production and quality costs. International Journal of Production Research, 48(24), 7357-7370. https://doi.org/10.1080/0020754 0903382881

Adil, A., \& Moutawakil, A. (2012). The quality cost reduction in hollow glass manufacturing by Taguchi method. Journal of Scientific Research, 4(1), 155-172. https://doi.org/10.3329/jsr.v4i1.7900

Al-Dujaili, M. A. A. (2013). Study of the relation between types of the quality costs and its impact on productivity and costs: A verification in manufacturing industries. Total Quality Management \& Business Excellence, 24(3/4), 397419. https://doi.org/10.1080/14783363.2012.669552

Aqlan, F., \& Al-Fandi, L. (2018). Prioritizing process improvement initiatives in manufacturing environments. International Journal of Production Economics, 196(February), 261-268. https://doi.org/10.1016/j.ijpe.2017 .12.004

Bakotic, D., \& Krnic, A. (2017). Exploring the relationship between business process improvement and employees' behavior. Journal of Organizational Change Management, 30(7), 1044-1062. https://doi.org/10.1108/JOCM-062016-0116

Boyce, J. M., DuPont, H. L., Massaro, J., Sack, D., \& Schaffner, D. W. (2012). An expert panel report of a proposed scientific model demonstrating the effectiveness of antibacterial handwash products. American Journal of Infection Control, 40(8), 742-749. https://doi.org/10.1016/j.ajic.2011.09.016

BS 6143 Part 1. (1990). Guide to determination and use of quality related costs. British Standards Institute, London

BS 6143 Part 2. (1990). Guide to determination and use of quality-related costs. British Standards Institute, London

Campanella, J. (1999). Principles of quality costs. 3rd ed. Milwaukee, WI: American Society for Quality

Caro, J., Salas, M., Ward, A., Sung, J., \& Shah, A. (2001). Confirmation of the decision rules and assumptions for a model of diabetes treatment using an expert panel. Value in Health, 4(2), 187. https://doi.org/10.1046/j.15244733.2001.40202-310.x

Cokins, G., \& Harris, M. (2006). Measuring cost of quality- myth or reality. American Society for Quality World Conference Proceedings, Session T110

Cooper, R., \& Kaplan, R. S. (1988). Measure costs right: Make the right decisions. Harvard Business Review, 66(5), 96103. http://host.uniroma3.it/facolta/economia/db/materiali/insegnamenti/588_3930.pdf

Crosby, P. B. (1979). Quality is free. New York: McGraw-Hill

Djekic, I., Zaric, V., \& Tomic, J. (2014). Quality costs in a fruit processing company: a case study of a Serbian company. Quality Assurance and Safety of Crops \& Foods, 6(1), 95-103. https://doi.org/10.3920/QAS2012.0200

Dybå, T. (2000). An instrument for measuring the key factors of success in software process improvement. Empirical Software Engineering, 5(4), 357-390, https://doi.org/10.1023/A:1009800404137

Fabianova, J., Janekova, J., \& Onofrejova, D. (2017). Cost analysis of poor quality using a software simulation. Amfiteatru Economic, 19(44), 181-196.

Fassoula, E. D. (2005). Reverse logistics as a means of reducing the cost of quality. Total Quality Management \& Business Excellence, 16(5), 631-643. https://doi.org/10.1080/14783360500077575 
Feigenbaum, A. V. (1956). Total quality control. Harvard Business Review, 34(6), 93-101.

Fine, C. H. (1986). Quality improvement and learning in productive systems. Management Science, 32(10), $1301-1315$. https://doi.org/10.1287/mnsc.32.10.1301

Glogovac, M., \& Filipovic, J. (2017). Quality costs in practice and an analysis of the factors affecting quality cost management. Total Quality Management \& Business Excellence, Published online 09 Jan 2017, https://doi.org/10.1080/14783363.2016.1273105

Goetsch, D. L., \& Davis, S. B. (2016). Quality Management for Organizational Excellence (8th edition). Pearson Education, New Jersey

He, D. (2010). Engineering quality systems: Cost of quality. Modern Applied Science, 4(5), $102-104$. http://www.ccsenet.org/journal/index.php/mas/article/viewFile/6029/4866 https://doi.org/10.5539/mas.v4n5p102

Ihrig, S., Ishizaka, A., \& Mohnen, A. (2017). Target setting for indirect processes: a new hybrid method for the continuous improvement management of indirect processes. Production Planning \& Control, 28(3), $220-231$. https://doi.org/10.1080/09537287.2016.1254830

ISO 9001:2015 - Quality management systems - Requirements. International Organization for Standardization, 2015

Jaju, S. B., Mohanty, R. P., \& Lakhe, R. R. (2009). Towards managing quality cost: A case study. Total Quality Management \& Business Excellence, 20(10), 1075-1094. https://doi.org/10.1080/14783360903247122

Juran, J. M., \& Gryna, F. M. (1998). Juran's quality control handbook, 5th ed. New York: McGraw-Hill

Juran, J. M., Gryna, F. M., \& Bingham, R. (1975). Quality control textbook. McGraw-Hill, New York

Jurburg, D., Viles, E., Tanco, M., \& Mateo, R. (2017). What motivates employees to participate in continuous improvement activities? Total Quality Management \& Business Excellence, 28(13/14), 1469-1488. https://doi.org/10. 1080/14783363.2016.1150170

Lari, A., \& Asllani, A. (2013). Quality cost management support system: an effective tool for organizational performance improvement. Total Quality Management \& Business Excellence, 24(3/4), 432-451. https://doi.org/10.1 080/14783363.2012.733258

Lim, C., Sherali, H. D., \& Glickman, T. S. (2015). Cost-of-Quality optimization via zero-one polynomial programming. IIE Transactions, 47(3), 258-273. https://doi.org/10.1080/0740817X.2014.928964

Lim, T. K., Jang, W. S., Choi, J. H., \& Lee, D. E. (2015). Stochastic quality-cost optimization system hybridizing multiobjective genetic algorithm and quality function deployment. Journal of Civil Engineering and Management, 21(4), 407-422. https://doi.org/10.3846/13923730.2014.890647

Martínez, J. M. B., \& Selles, M. E. S. (2015). A fuzzy quality cost estimation method. Fuzzy Sets and Systems, 266(2015), 157-170. https://doi.org/10.1016/j.fss.2014.12.014

Masser, W. J. (1957). The quality manager and quality costs. Industrial Quality Control, 14(4), 5-8

Matthews, R. L., MacCarthy, B. L., \& Braziotis, C. (2017). Organisational learning in SMEs: A process improvement perspective. International Journal of Operations \& Production Management, 37(7), 970-1006. https://doi.org/10.11 08/IJOPM-09-2015-0580

Mizla, M., \& Pudlo, P. (2012). Quality costs structure and company sensitivity to fluctuation of economy. E \& M Ekonomie A Management, 15(1), 44-56

Oppermann, M., Sauer, W., \& Wohlrabe, H. (2003). Optimization of quality costs. Robotics and Computer-Integrated Manufacturing, 19(1/2), 135-140. https://doi.org/10.1016/S0736-5845(02)00070-4

Ozkan, S., \& Karaibrahimoglu, Y. Z. (2013). Activity-based costing approach in the measurement of cost of quality in SMEs: a case study. Total Quality Management \& Business Excellence, 24(4), 420-431. https://doi.org/10.10 80/14783363.2012.704286

Rehacek, P. (2018). Costs of quality or quality costs. International Journal of Advanced and Applied Sciences, 5(2), 8-13. https://doi.org/10.21833/ijaas.2018.02.002

Ross, D. T. 1977. Structured analysis (SA): A language for communicating ideas. IEEE Transactions on Software Engineering, 3(1), 16-34. https://doi.org/10.1109/TSE.1977.229900

Sandoval-Chavez, D. A., \& Beruvides, M. G. (1998). Using opportunity costs to determine the cost of quality: A case study in a continuous-process industry. Engineering Economist, 43(2), 107-124. https://doi.org/10.1080/00 137919808903192 
Maja Glogovac, Jovan Filipovic, Nedeljko Zivkovic, Veljko Jeremic. A Model for Prioritization of Improvement ...

Sansalvador, M. E., \& Brotons, J. M. (2013). Quality cost analysis: a case study of a Spanish organisation. Total Quality Management \& Business Excellence, 24(3/4), 378-396. https://doi.org/10.1080/14783363.2012.734951

Schiffauerova, A., \& Thomson, V. (2006). A review of research on cost of quality models and best practices. International Journal of Quality \& Reliability Management, 23(6), 647-669. https://doi.org/10.1108/0265 6710610672470

Vaxevanidis, N. M., \& Petropouolos, G. (2008). A literature survey of cost of quality models. Journal of Engineering Annals, 6(3), 274-283

Veldman, J., \& Gaalman, G. J. C. (2015). Competitive investments in cost reducing process improvement: The role of managerial incentives and spillover learning. International Journal of Production Economics, 170, Part B, 701-709. https://doi.org/10.1016/j.ijpe.2015.08.016

Voros, J. (2013). Multi-period models for analyzing the dynamics of process improvement activities. European Journal of Operational Research, 230(3), 615-623. https://doi.org/10.1016/j.ejor.2013.04.036

Yim, A. (2014). Failure Risk and Quality Cost Management in Single versus Multiple Sourcing Decision. Decision Sciences, 45(2), 341-354. https://doi.org/10.1111/deci.12070

Yin, R. K. (2013). Case study research: Design and methods. Sage publications.

The article has been reviewed.

Received in April 2016; accepted in June 2019. 